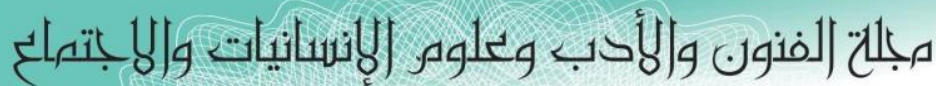

Journal of Arts, Literature, Humanities and Social Sciences

ISSN online: 2414 - 3383

ISSN print: 2616 - 3810

(45) (40)

November 2019

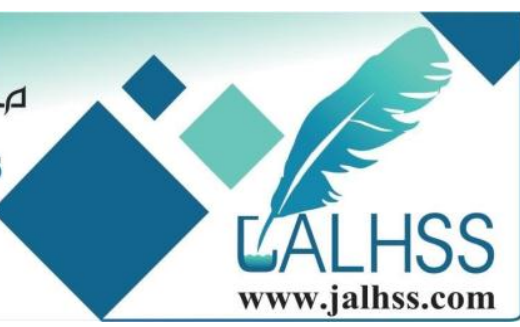

\title{
الاختلاف في مصادر التصوف الإسلامي
}

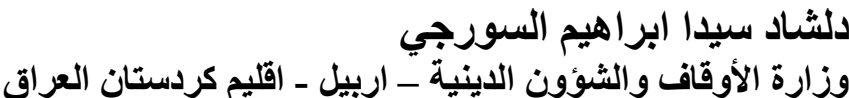 \\ malik9dilshad@gmail.com :الإيميل الاوفيل -
}

الملخص

الفلسفة الإسلامية ذات فروع متعددة، ومن فروعها التصوف الإسلامي، وبما أن التصوف لم يكن بهذا الاسم الموجود الآن في زمن رسول اله ( صلى الله عليه وسلم )؛ فإن معظم فروعه حوله خلاف وجدل؛ من اسمه، ونشأته، ومصطلحاتها... - 2.

ومن فروعه المختلف فيه هو مصادر التصوف الإسلامي؛ حيث أصبحت مصادر التصوف الإسلامي مثار جدل ومناقشة في هل التصوف الإسلامي نانشيء من المصادر الأصلية الحققية للدين الإسلامي، أو أن التصوف الإسلامي أخذ بذوره الأولى من مصادر أخرى غير إسلامية؛ وذلك نتيجة اتساع الرقعة الإسلامية واحتكالك الفلسفات والحضار ات و الثقافات للشعوب غير العربية التي كانت تدين بدين آخر ودخلت في الإسلام. وحول هذا الموضوع ( مصادر التصوف الإسلامي ) تحدث كثير من المفكرين والعلماء، وسلطوا الضوء على نشأة التصوف الإسلامي و المر احل التي مر بها التصوف، فأرجعوا أصل التصوف إلى الإسلام نفسه من القرآن و السنة النبوية الشريفة، مع الاعتر اف بأن بعض المتصوفة ربما تأثروا بثقافات غير هم. وكذلك المستشرقون تطرقوا إلى هذا الجانب من الفلسفة الإسلامية، وأخذوا يكتبون عن التصوف ونشأته ورجاله ومصطلحاته، وقارنوا بين الحباة الروحية في الإسلام والأديان الأخرى، لكن الدافع الذي دفع المستشرقين إلى الى در اسة هذا الموضوع مختلفًا مع الدافع الذي دفع غير هم إلى دراسة القضية نفسها؛ فجاءت النتيجة مختلفة لنتائج غير هم حول مصادر التصوف الإسلامي؛ حيث معظم المستشرقين أرجعوا التصوف إلى مصادر غير إسلامية. آمل أن يكون هذا البحث المنو اضع نابعًا من نفس صافية وروح علمية، وأن تكون قد أصاب الحقيقة في هذا 


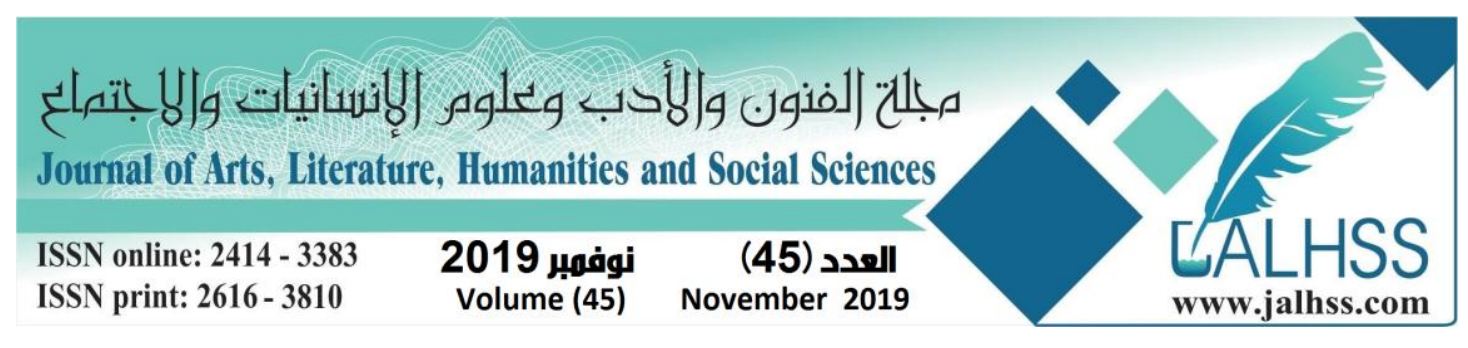

\title{
Differences In The Sources of Islamic Mysticism
}

\section{Delshad Sida Ibrahim Al-Surji}

\begin{abstract}
Islamic philosophy has many branches, including branches of Islamic mysticism, and since mysticism was not that name now in the time of the Messenger of Allah (peace be upon him); most of the branches around him controversy; controversy; of his name, and his upbringing, and terminology...

Sources of Islamic mysticism have become controversial and debated in whether Islamic mysticism originated from the true sources of the Islamic religion, or that Islamic mysticism took its first seeds from other non-Islamic sources as a result of the expansion of the Islamic area and the friction of philosophies and civilizations. The cultures of non-Arab peoples who were religions of another religion and entered into Islam.

On this subject (sources of Islamic mysticism) many thinkers and scholars spoke, and highlighted the emergence of Islamic mysticism and the stages experienced by the mysticism, they attributed the origin of the mysticism to Islam itself from the Koran and the Sunnah, while recognizing that some Sufis may have been influenced by the cultures of others.

As well as Orientalists touched on this aspect of Islamic philosophy, and began to write about Sufism and its origins, men and terminology, and compared the spiritual life in Islam and other religions, but the motivation that led Orientalists to study this issue is different with the motivation that led others to study the same issue; The results of others on the sources of Islamic mysticism, where most Orientalists attributed the mysticism to non-Islamic sources.

I hope that this modest research stems from the same pure and scientific spirit, and that it has struck the truth in this regard.
\end{abstract}




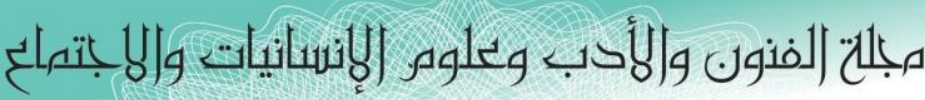
Journal of Arts, Literature, Humanities and Social Sciences

ISSN online: 2414 - 3383

ISSN print: 2616 - 3810

2019 نوفر نوبر Volume (45)
العدد (45) November 2019

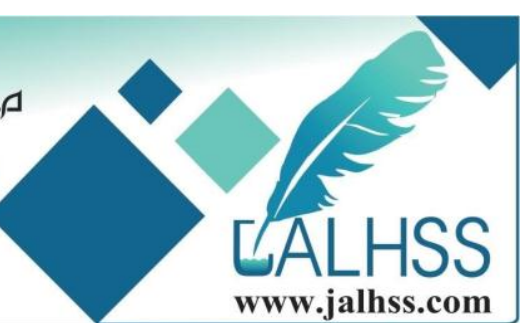

المقدمة

الحمد لله نحمده ونستعينه ونستغفره ونستهديه ونعوذ باله من شرور أنفسنا ومن سيئات أعمالنا، من يهده الله

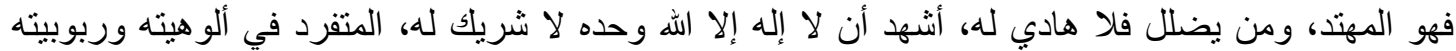

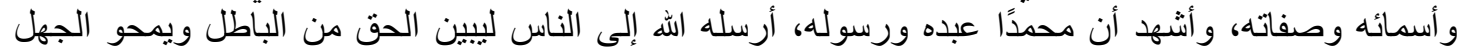

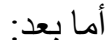

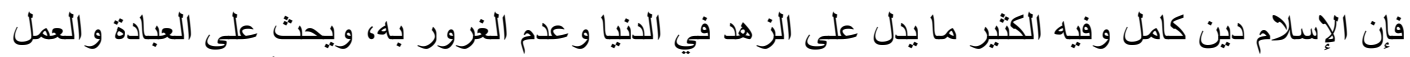

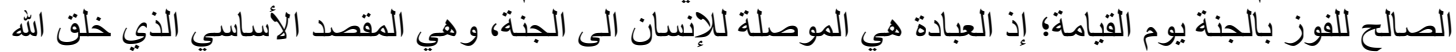

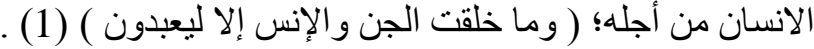

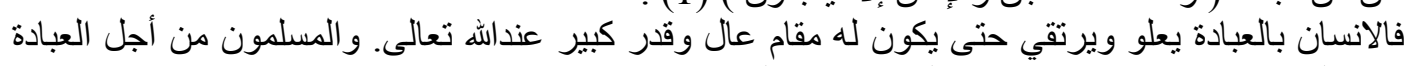

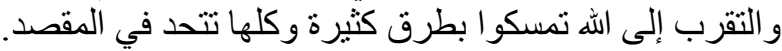

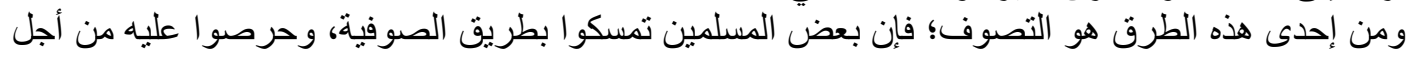
العبادة وتصفية القلوب وتحصيل السون السعادة.

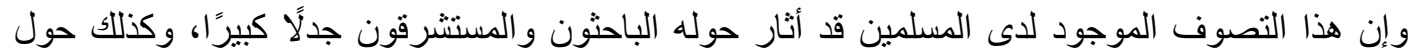

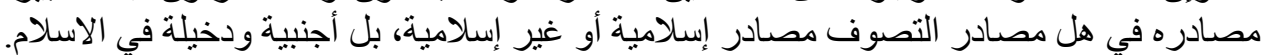

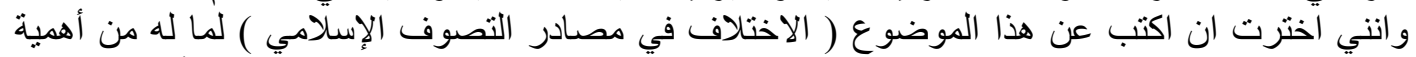

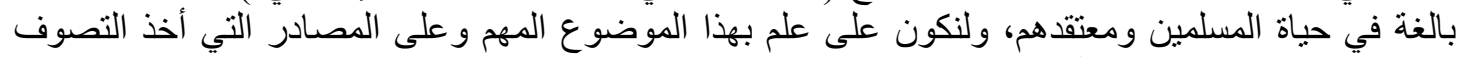

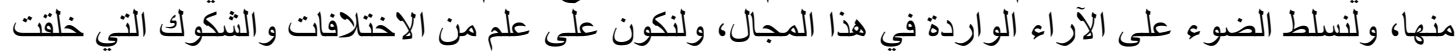
حول مصادر التصوف الإسلامي.

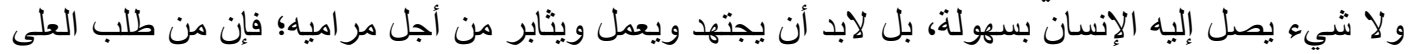

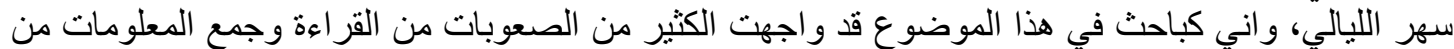

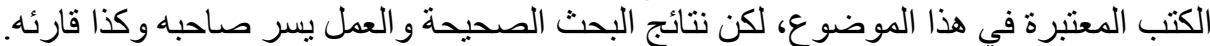

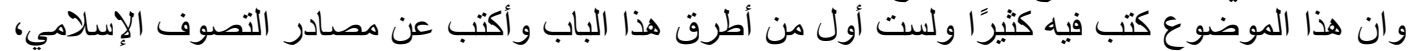

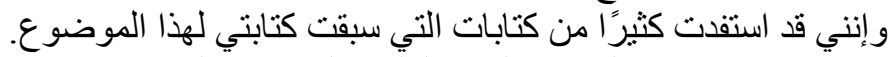

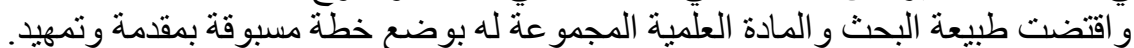

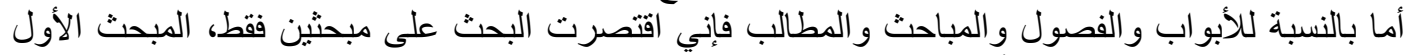

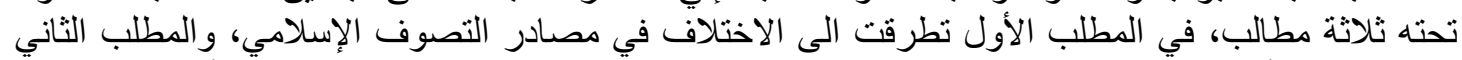

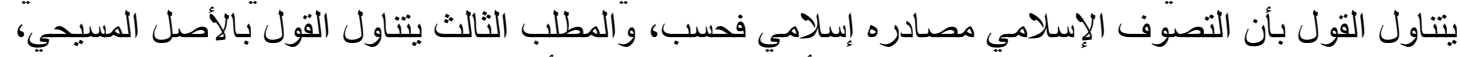

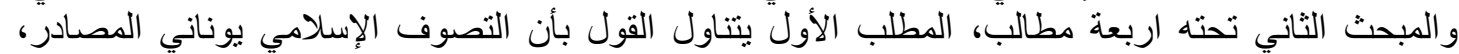

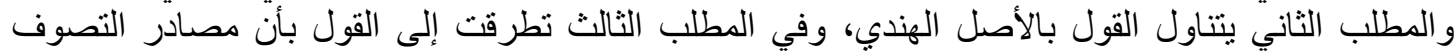

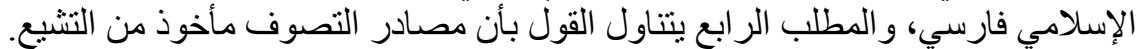

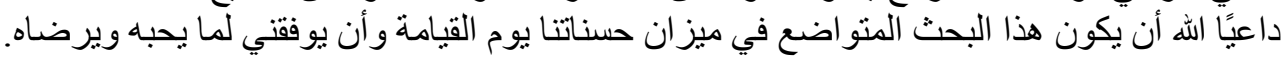

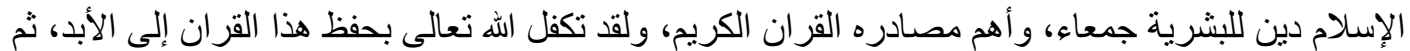

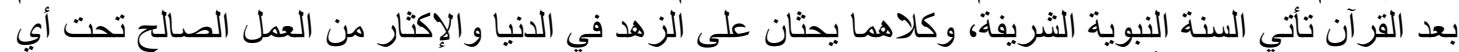

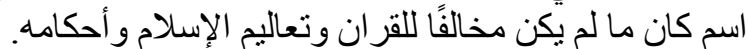

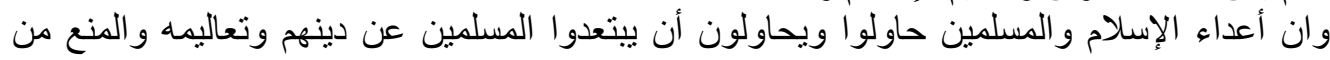

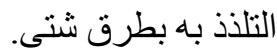

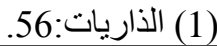




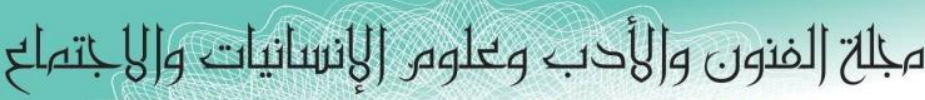
Journal of Arts, Literature, Humanities and Social Sciences

ISSN online: 2414 - 3383

ISSN print: 2616 - 3810

\section{9 نوفر \\ Volume (45)}

العدد (45)

November 2019

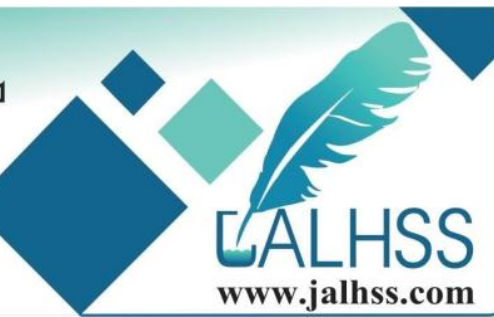

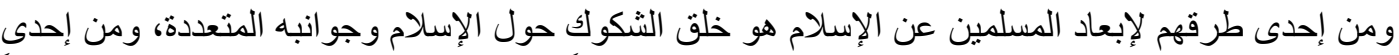

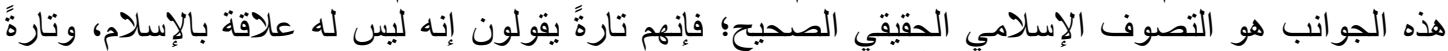

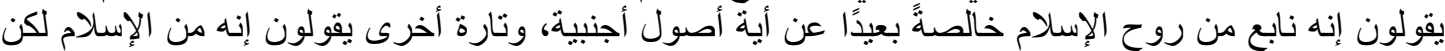

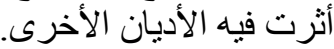

المهم عندهم هو إبعاد المسلمين عن دينهم وتعاليمه بأية طريقة كان وتحت أي اسم كان، وذلك موافقا لقوله

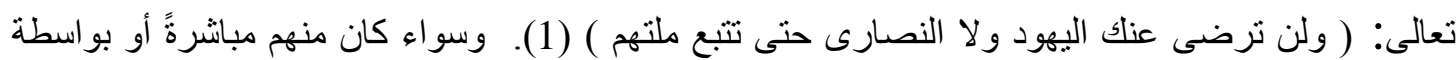

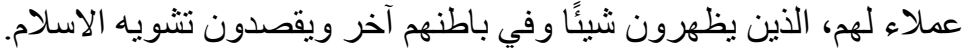

\section{المبحث الاول}

\section{المطلب الأول \\ الاختلاف في مصادر التصوف الإسلامي}

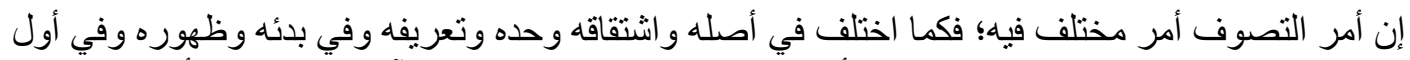

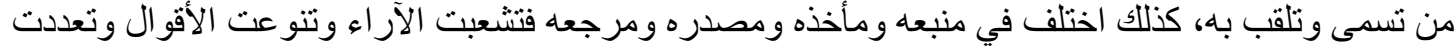
الأفكار في هذا.

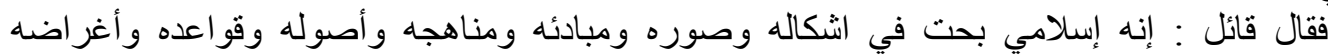

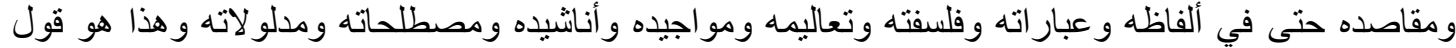

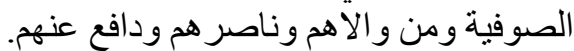
وقال قوم: لا علاقة له بالإسلام إطلافًا قريبة و لا بعيدة، في اليوم الذي نشأ فيه و ولا بعد تطوره، وهو وهو

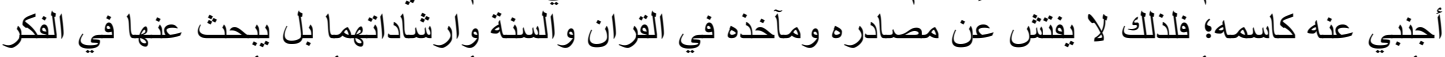

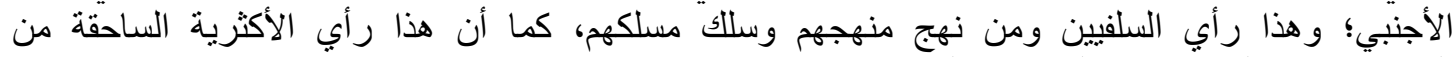
المستشرقين، و الكثيرين من الباحثين و المفكرين.

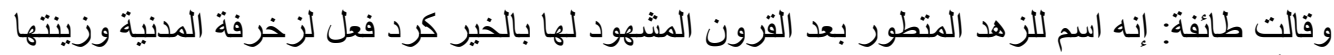

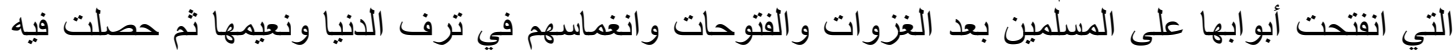

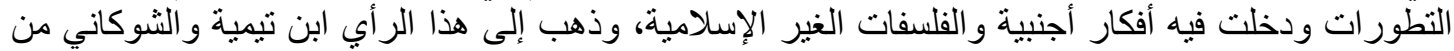

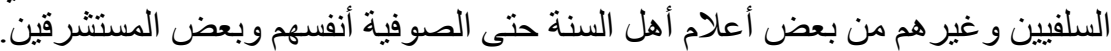

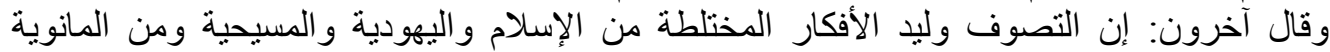

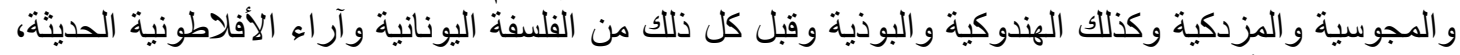
وتمسك بهذا الر أي بعض الكتاب في الصوفية ون الكن المسلمين و غير المسلمين(2).

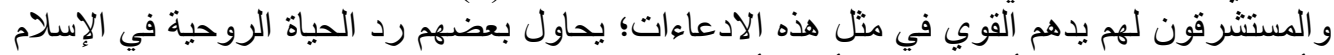

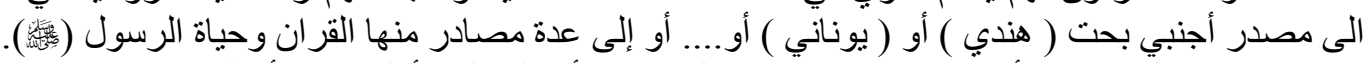

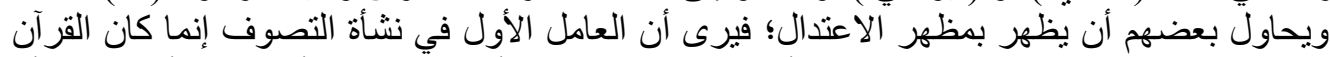

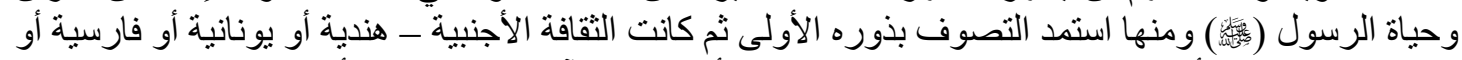

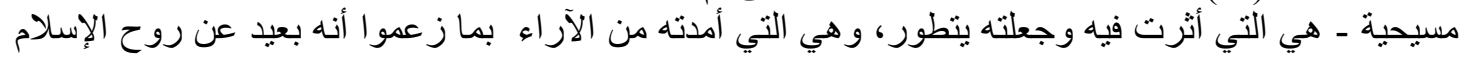

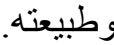




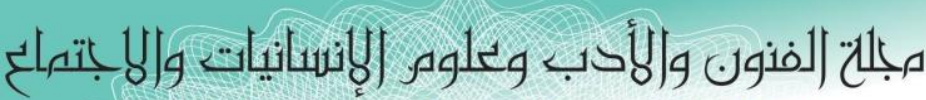
Journal of Arts, Literature, Humanities and Social Sciences

ISSN online: 2414 - 3383

ISSN print: 2616 - 3810

\section{9 نوفر Volume (45)}

(45) (4015) November 2019

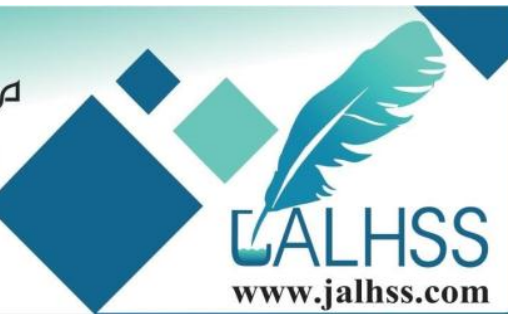

وبرغم ان الاستاذ ( لويس ماسينيون )(1) يقول في صراحة: أما دراسة مصادر التصوف فإن الثقة بينتا

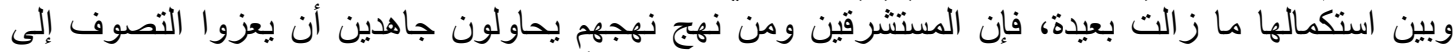

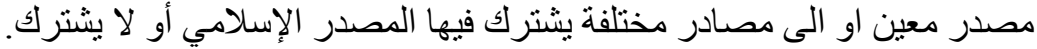

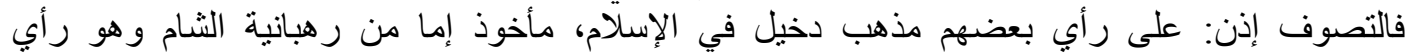
(ميركس)، و إما من ( أفلاطونية اليونان الجديدة )، و إما من ( زر ادشتية الفرس )، وإما من ( فيدا الهنود ) وهو

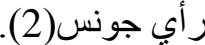
نحاول بإذنه تعالى ان نتكلم فيما بعد عن هذه الآر اء كلها على حدة ونبين السبب في هذه الأقوال.

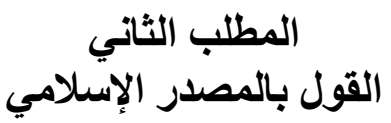

انقسم الباحثون حول هذا الموضوع إلى فريقين: فريق يرى أن نشأة التصوف الإسلامي ترجع إلى عناصر

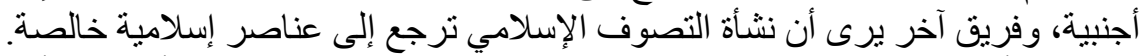

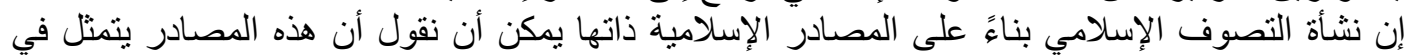

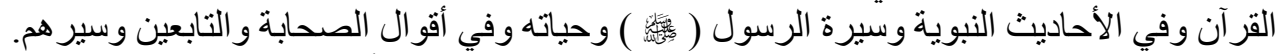

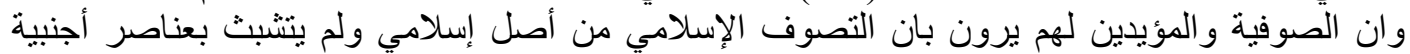

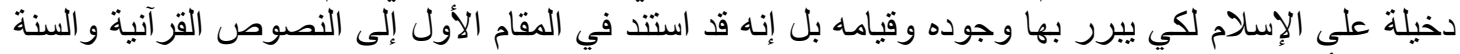

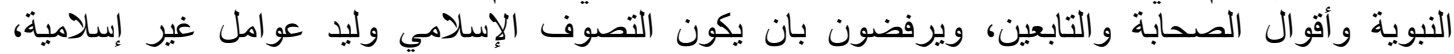

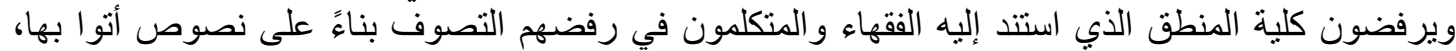

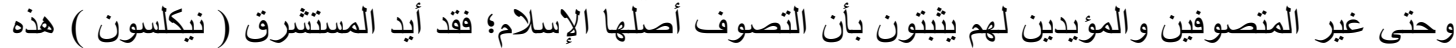

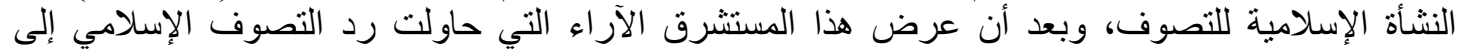

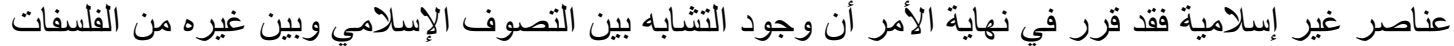

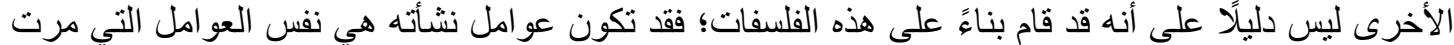

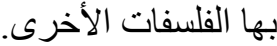

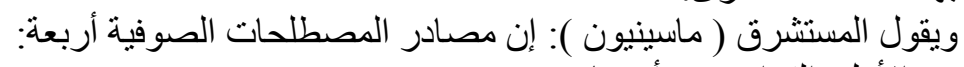
الأول: القران وهو أهمها.

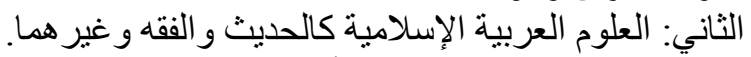

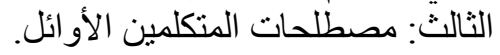
الر ابع: اللغة العلمية التي تكونت في الثرات الثرق في القرون الستة للمسيحية الأولى من لغات أخرى كاليونانية و الفارسية و غير ها و أصبحت للغة التئة العلم وألفلسفة.

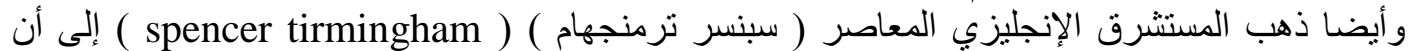

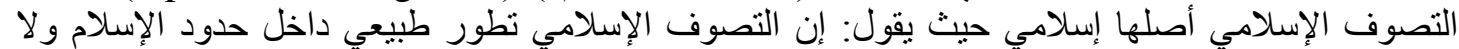

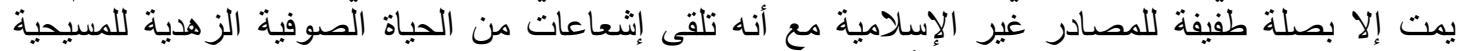

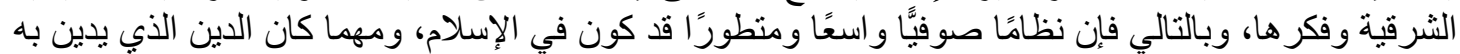

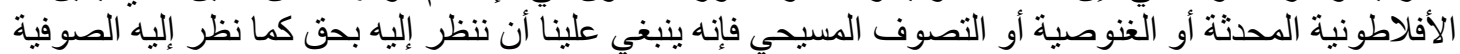
أنفسهم على أنه النظرية الباطنة للإسلام والسر الذورة الذي تضمنه القران(3).

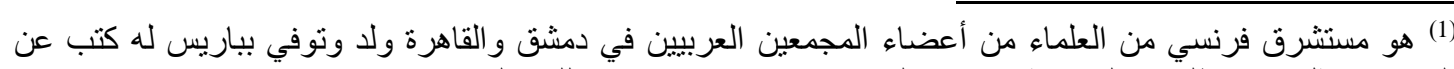

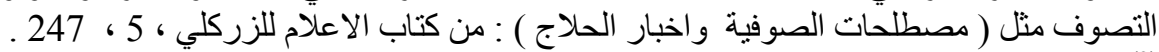

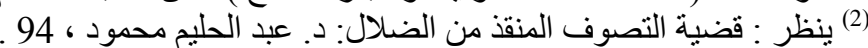

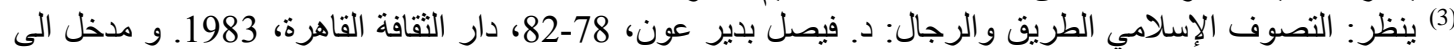

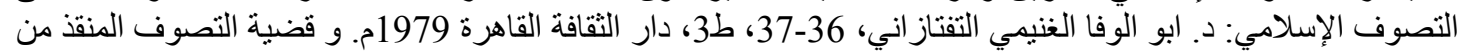




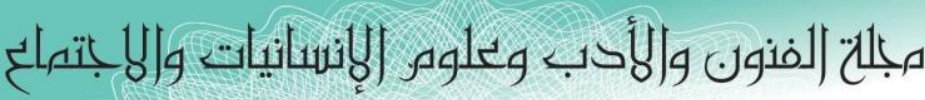
Journal of Arts, Literature, Humanities and Social Sciences

ISSN online: 2414 - 3383

ISSN print: 2616 - 3810

\section{9 نوفر Volume (45)}

العدد (45) November 2019

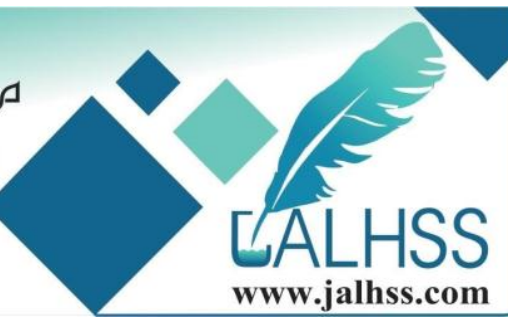

قلنا إن الصوفية ومؤيديهم يرجِّعون أصل التصوف إلى القران و السنة وحياة الصحابة و التابعين:

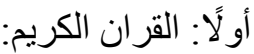
يرسم الصوفية طريقًا بسلكه كل مريد وتابع لكي يصل إلى الله تعالى، وهذا الطريق الصوفي بعتمد على الطي الطي

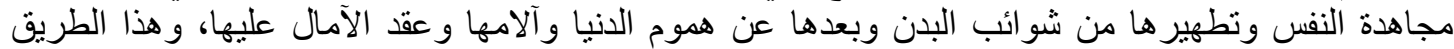

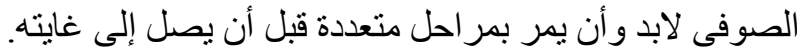

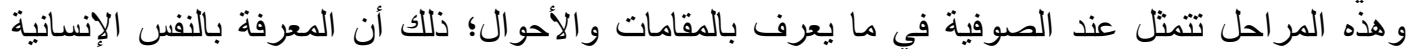

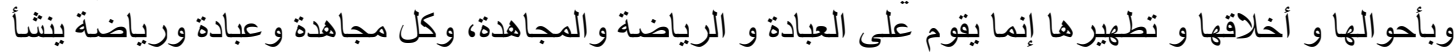

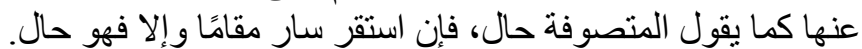

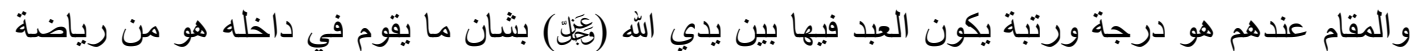

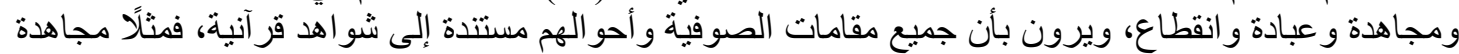

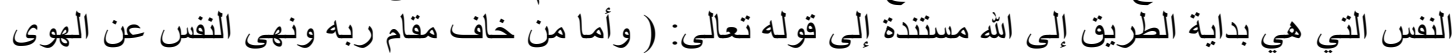

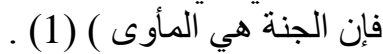

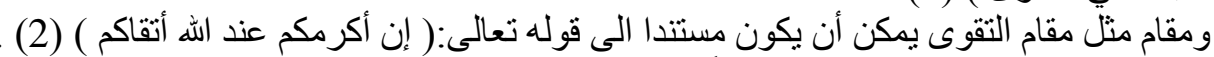

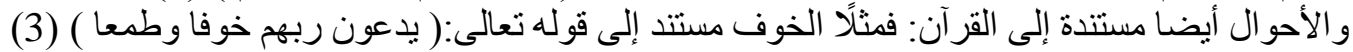

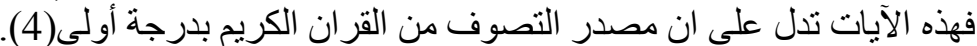

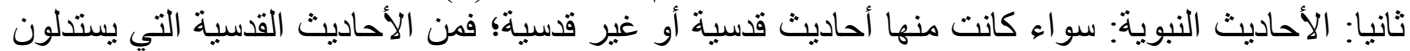

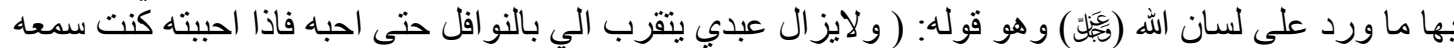

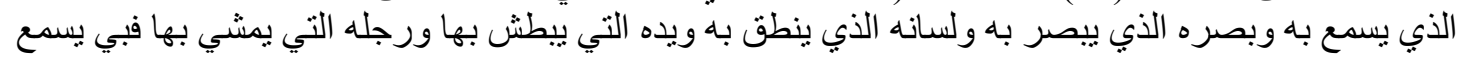

وبي يعقل وبي يبطش وبه وبي يمشي لوني )(5).

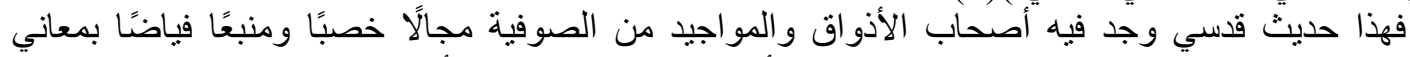

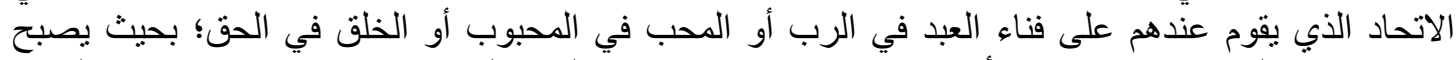

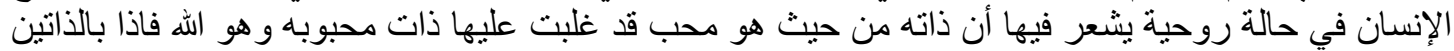

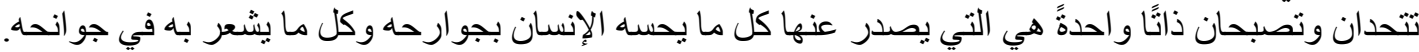

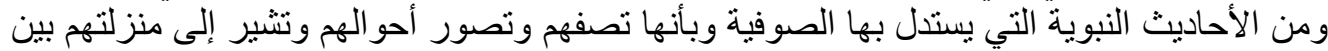

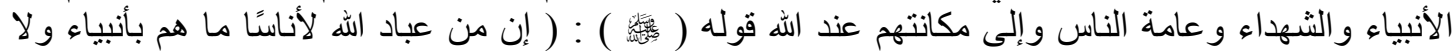

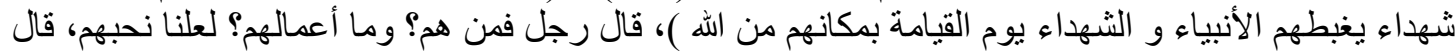

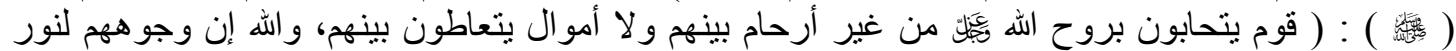

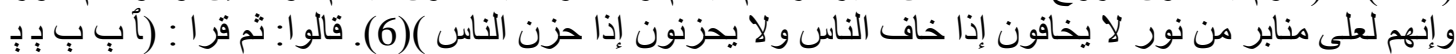

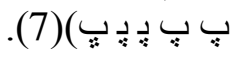

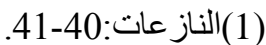

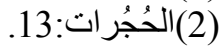

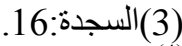

(4) ينظر: التصوف الإسلامي الطريق و الرجال: د. فيصل بدير عون، 82-85. و مدخل الى التصوف الإسلامي: د. ابو

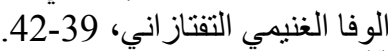

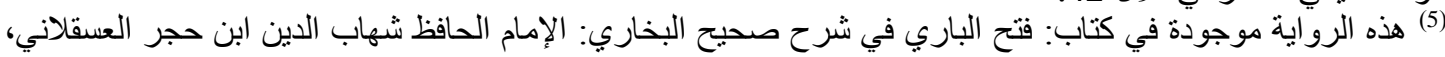

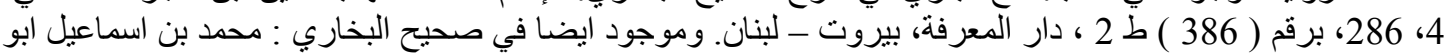

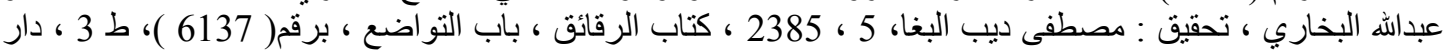

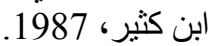
(6) سنن ابي داود: سليمان بن الأشعث ابو داود السجستاني ، تحقيق: محمد محي الدين عبدالحميد،3 ، 288، كتاب الاجارة

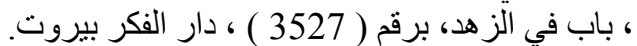

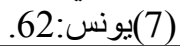




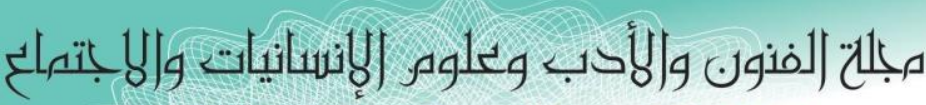
Journal of Arts, Literature, Humanities and Social Sciences

ISSN online: 2414 - 3383

ISSN print: 2616 - 3810

2019 نوفير Volume (45)

\section{(45) (40)}

November 2019

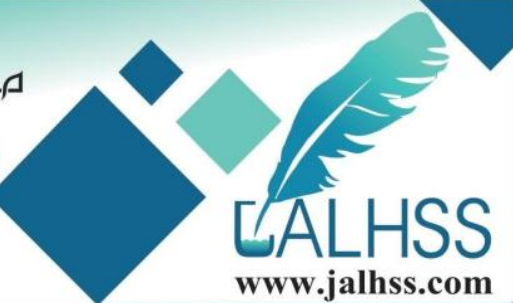

www.jalhss.com

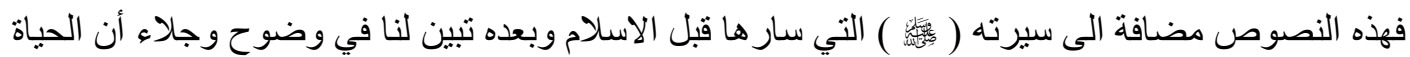

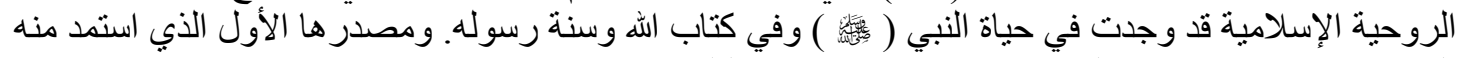

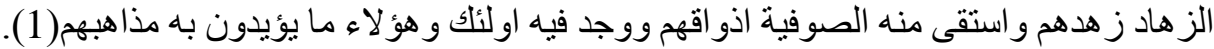

و استدلوا بهذا الحديث ايضا ( از هد في الدنبا يحبك الله و از هد فيما في ايدي الهي الناس يحبك الناس )(2).

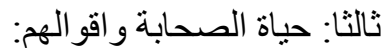

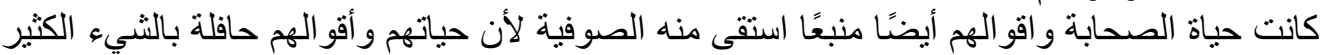

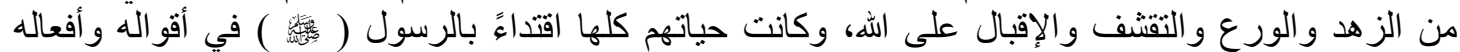

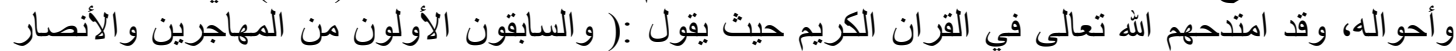

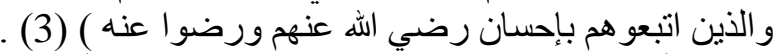

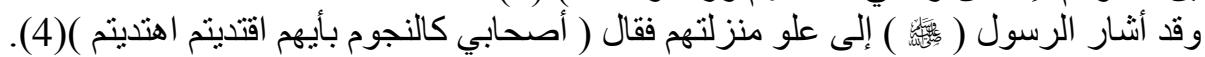

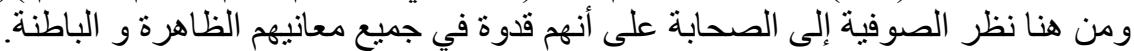

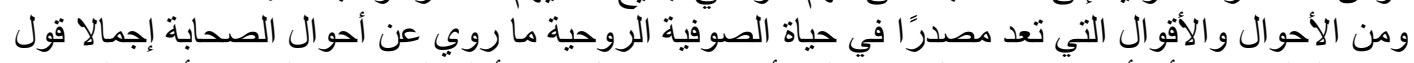

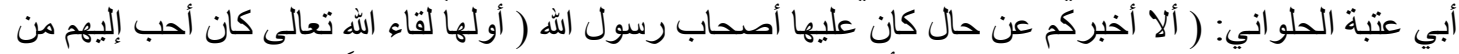

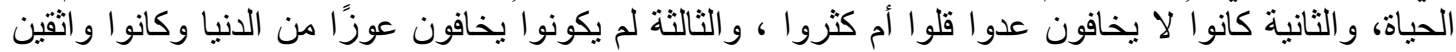

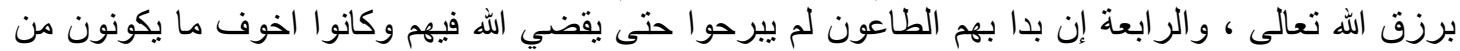

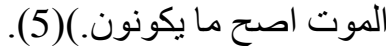

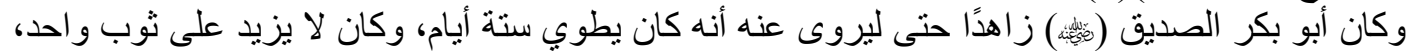

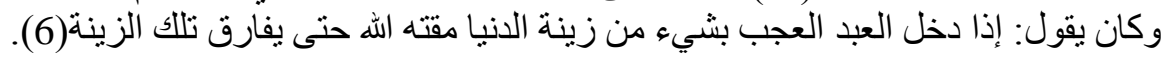

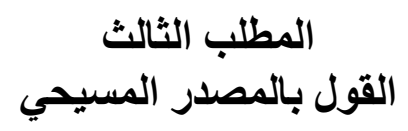

ذهب فريق من الباحثين إلى أن في الحياة الروحية في الإسلام طائفة من العناصر التي ترجع إلى أصول

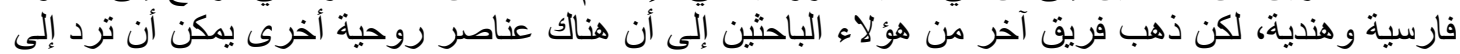

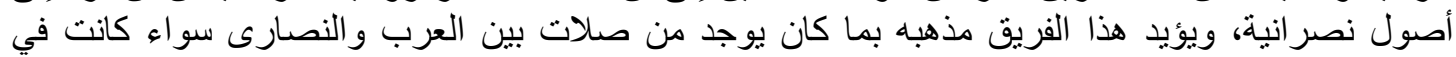

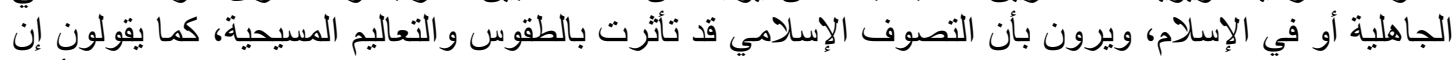

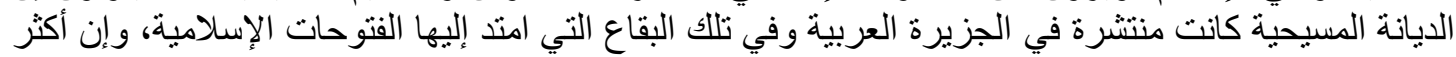

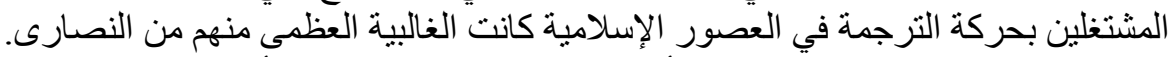

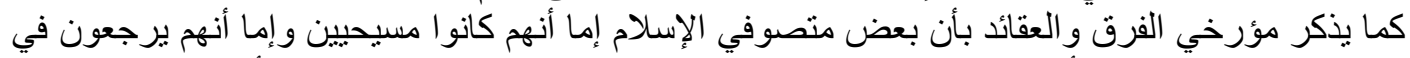

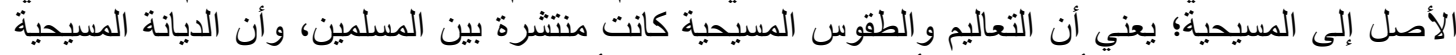

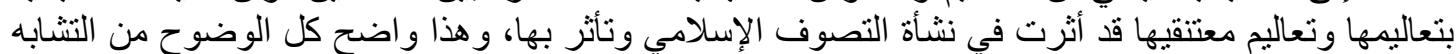

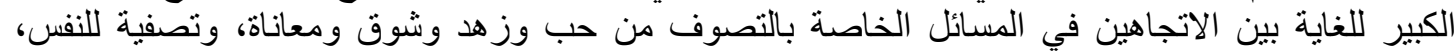

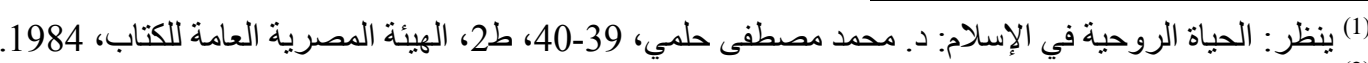
(2) المعجم الكبير: سليمان بن الحمد ابو القاسم الطبراني، تحقيق: حمدي بن عبد عبدالحميد السلفي، 6 ، 193 ، ط 2 2، مكتبة

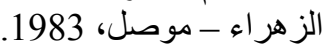

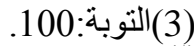

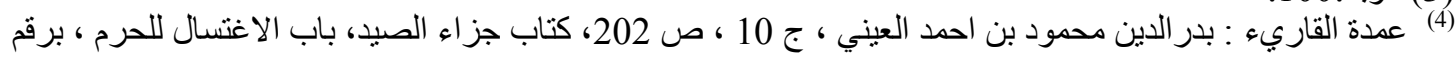

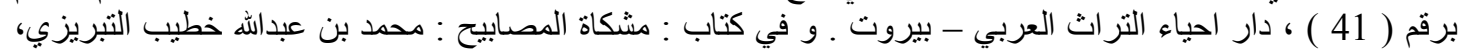

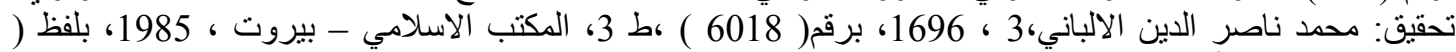

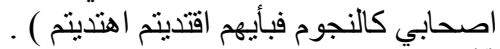
(50) اللمع: ابو نصر السراج الطوسي، تحقيق د. عبدالحليم محمود و طه عبدالباقي سرور، 167، مطبعة السعادة-مصر

(6) مدخل الى التصوف الإسلامي: د. ابو الوفا الغنيمي التفتاز اني، 51. 


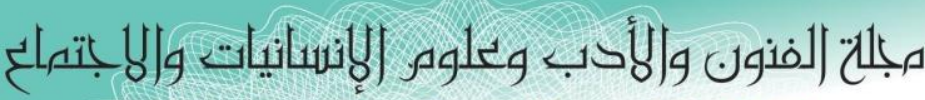
Journal of Arts, Literature, Humanities and Social Sciences

ISSN online: 2414 - 3383

ISSN print: 2616 - 3810

\section{9 نوفر Volume (45)}

(45) (40) November 2019

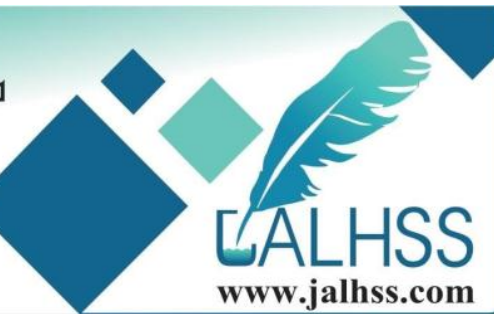

وتطهير للقلوب، ومعاينة لله، وحب الفقر ، و البعد عن الاهتمام اهتمامًا رئيسيًّا بشؤون الدنيا، وأن بعض النهان النظريات

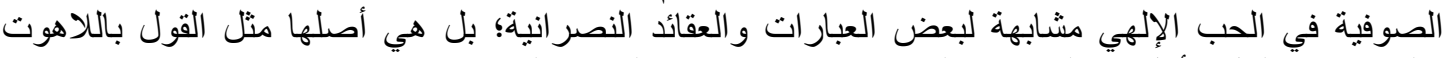

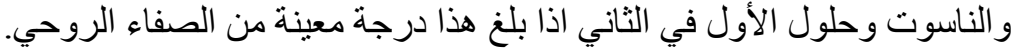

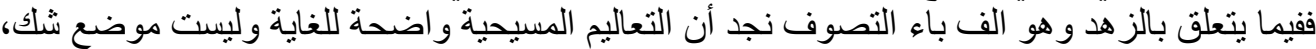

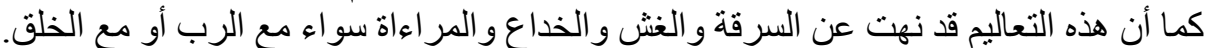

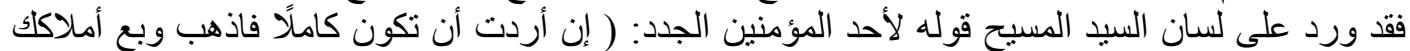
واعط الفقر اء فيكون للك كنز في السماء وتعال اتبعني التعي ).

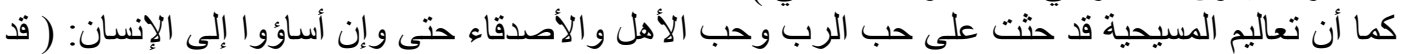

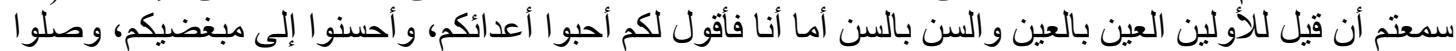

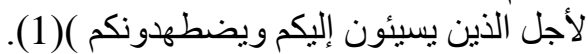

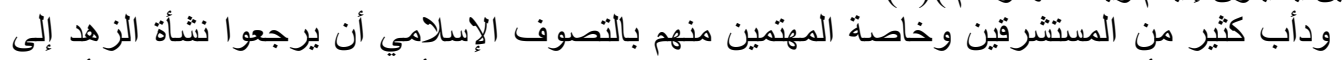

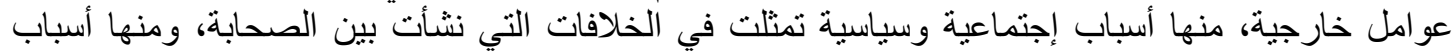

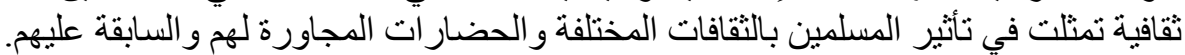

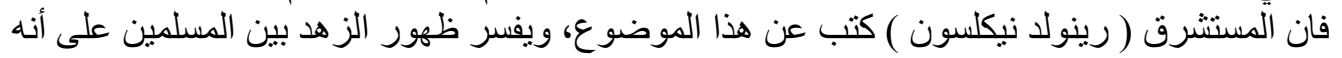

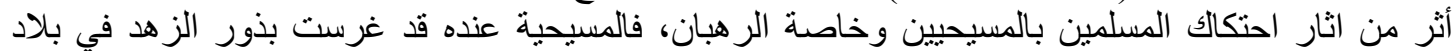

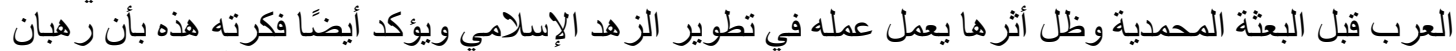

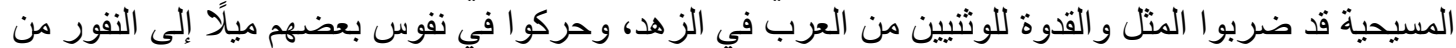

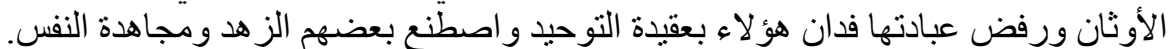

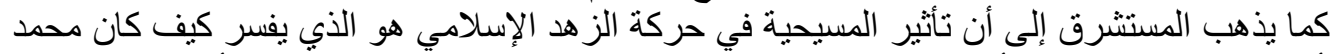

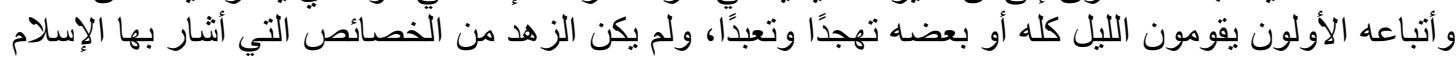

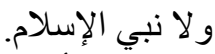
ويمكن أن نلخص راي نيكلسون في امور محددة:

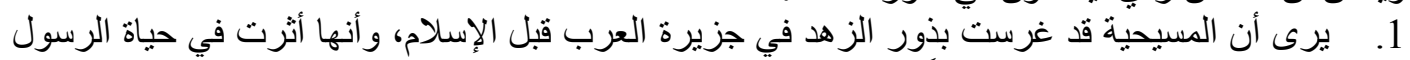
وصحابته فكانو ايقومون الليل عبادة وتبتلاً محاكاة للمسيحية.

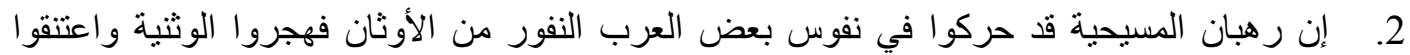
التوحيد متأثرين بالر هبان المسيحيين.

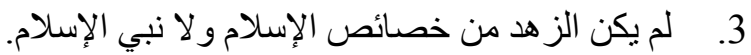

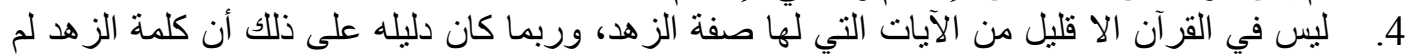
ترد في القران إلآ مرة واحدة.

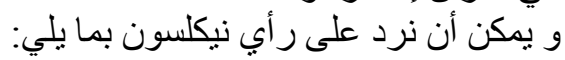

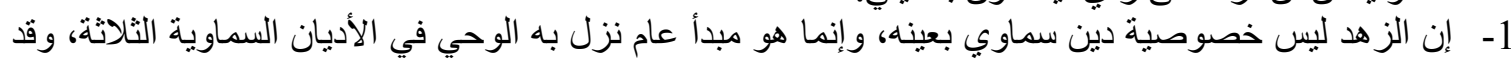

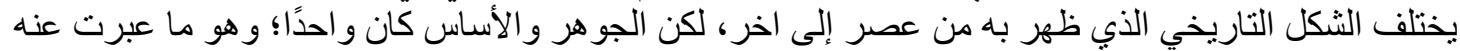

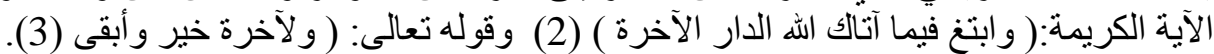

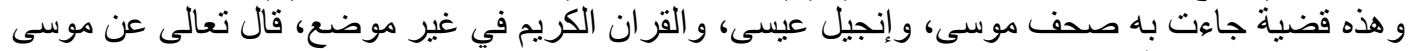

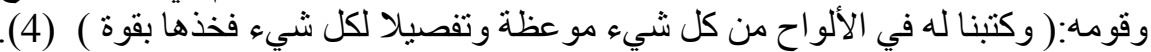

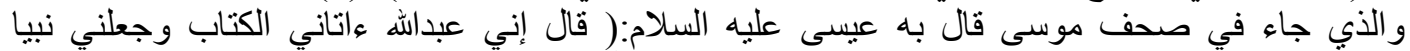
وجعلني مباركا أين ما كنت و أوصاني بالصلاة و الزكاة ما دمت حيَّا ) (5).

(1) ينظر : التصوف الإسلامى الطريق و الرجال: د. فيصل بدير عون، 63-65. الحياة الروحية في الإسلام: د. محمد مصطفى حلمي، 54-54. (3) (القصص: (3) (3) الأعلى:17. 


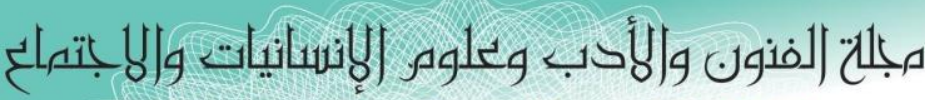
Journal of Arts, Literature, Humanities and Social Sciences

ISSN online: 2414 - 3383

ISSN print: 2616 - 3810

\section{9 نوفر Volume (45)}

العدد (45) November 2019

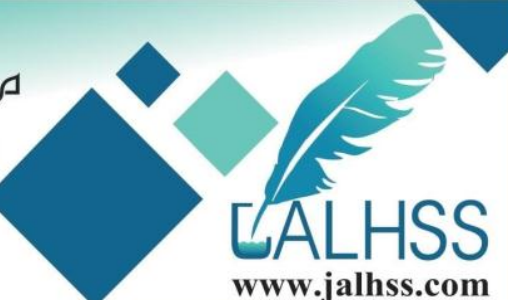

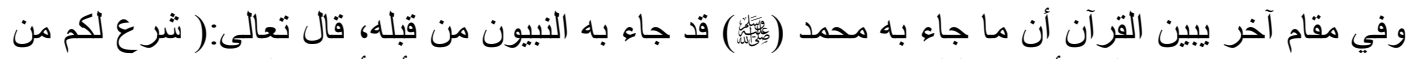

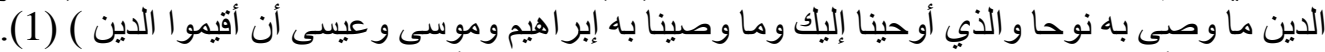

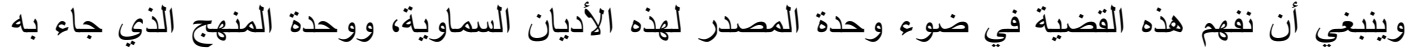

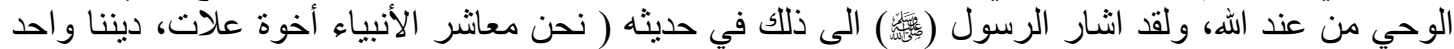

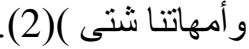

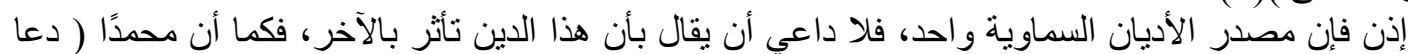

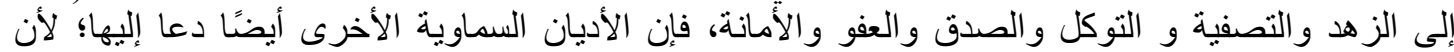

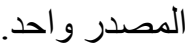

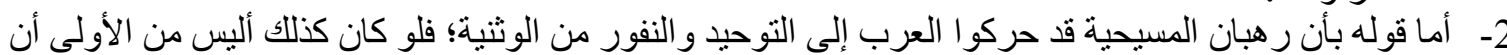

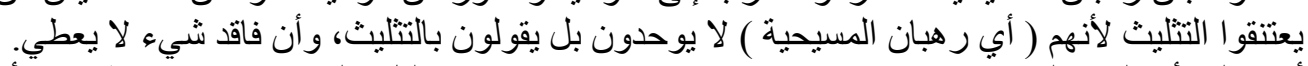

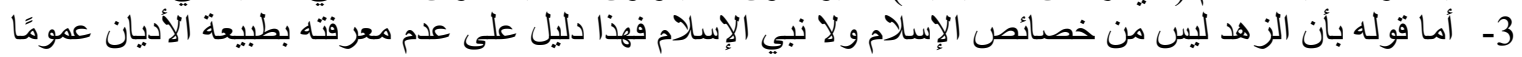

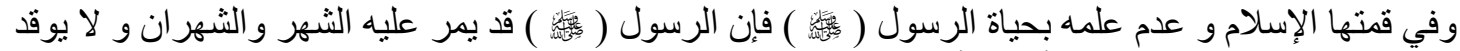

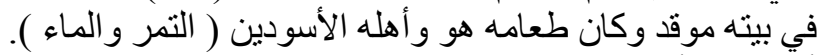

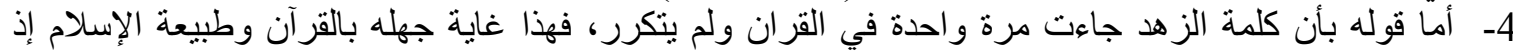

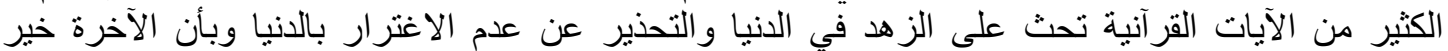

وأبقى.)

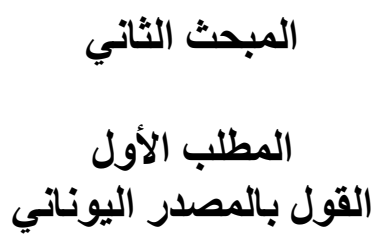

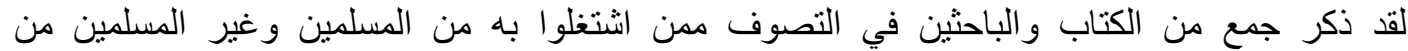

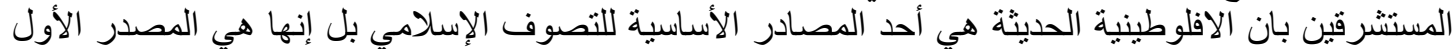

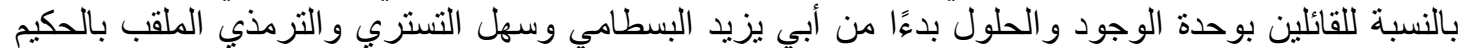

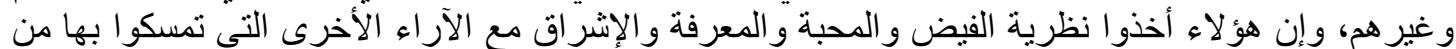

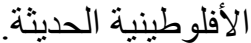
يقول صوفي معاصر: و أما وحدة الوجود الحلولية التي تجعل من الله كائنًا يحل في مخلوقاته أو الاتحادية

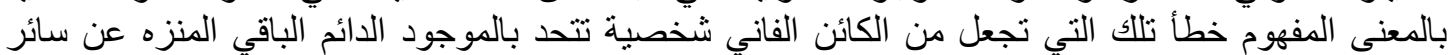

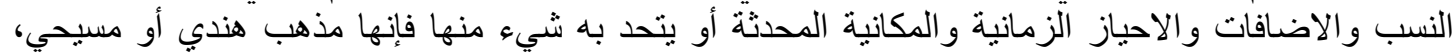

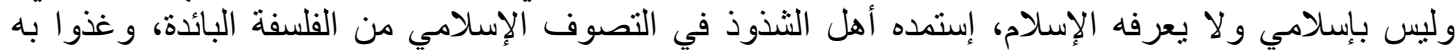

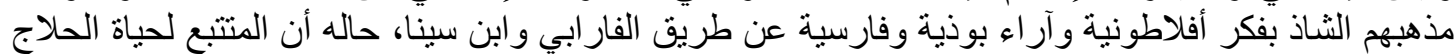

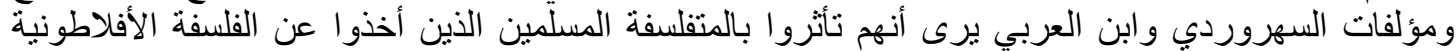

القديمة والأفلاطونية الحديثة و الأرسطو طاليسية.

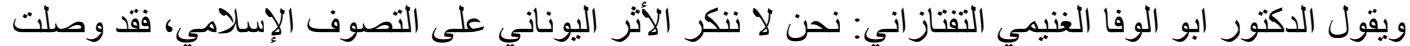

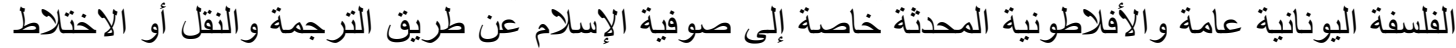
مع رهبان النصارى في الرها وحر ان، وقد خضع المسلمون لسلطان ارسطو، ولئ وليس من شك أن فلسفة الإنة ألفلوطين

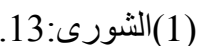
(2) لم احصل على هذه الرواية بل حصلت على رواية قريبة منها ، في كتاب : صحيح مسلم : مسلم بن الحجاج ابو الحسين الحسين

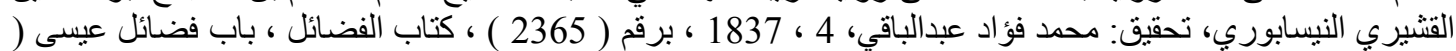

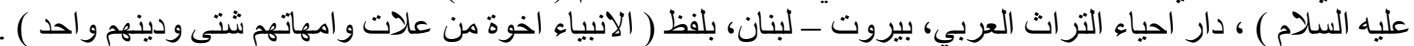

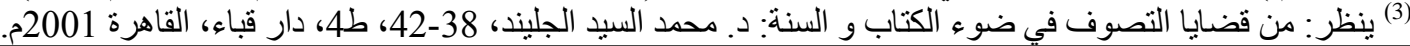




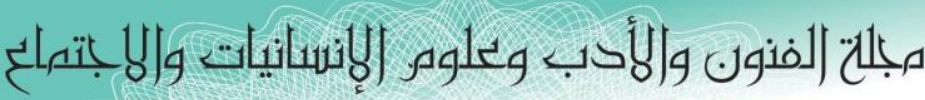
Journal of Arts, Literature, Humanities and Social Sciences

ISSN online: 2414 - 3383

ISSN print: 2616 - 3810

\section{9 نوفر Volume (45)}

العدد (45) November 2019

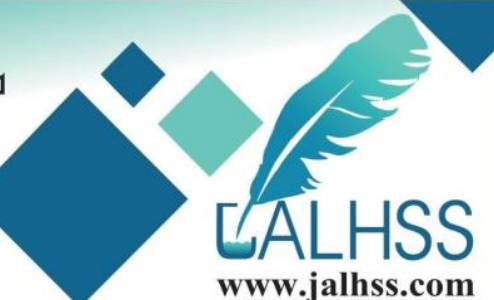

السكندري التي تعتبر أن المعرفة مدركة بالمشاهدة في حال الغيبة عن النفس وعن العالم المحسوس كان لها أثرها

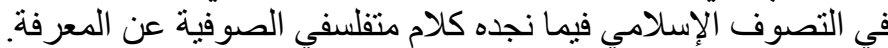

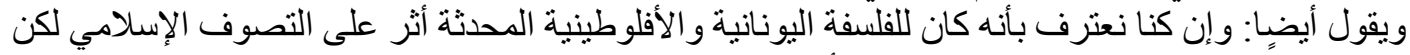

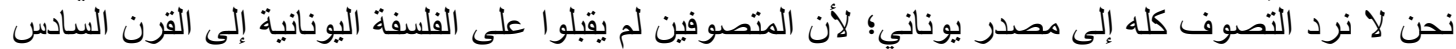

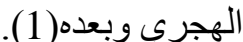

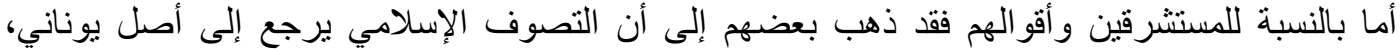

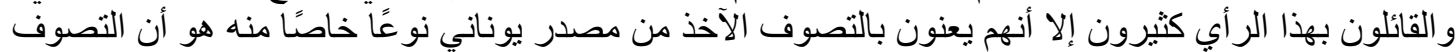

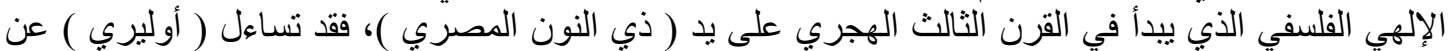

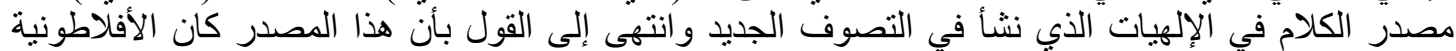
المحدثة.

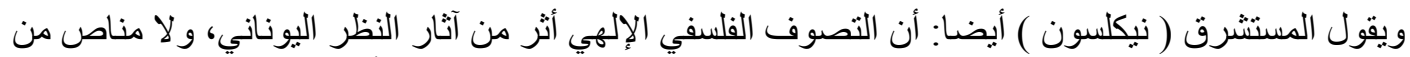
الاعتراف بما في التصوف من امتزاج الفكر اليوناني والدين الثرقي لاسيما الأفلاطونية التحدثة والثينة المانوية

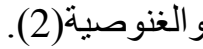
و القائلون بهذا الر أي برون بأن المتصوفة أخذوا في تدعيم مبادئهم وأفكار هم عن الأفكار اليونانية المتعددة المذاهب و الطر ائق ولعل من أبرز ها العا الأفكار الآتية:

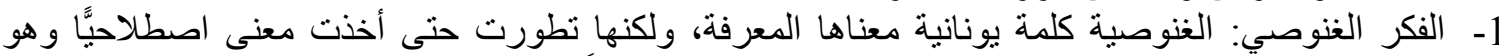

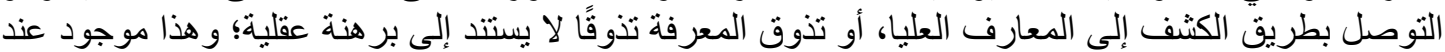

وقد ذهب بعض الباحثين الأوروبيين إلى أنه مادامت كلمة ( صوفية ) مستمدة من كلمة ( سوفيا ) الصوفية.

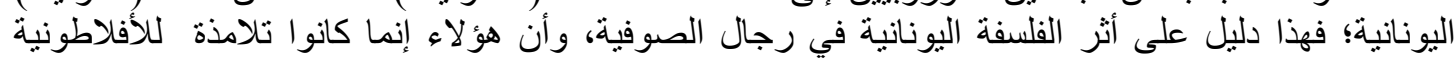

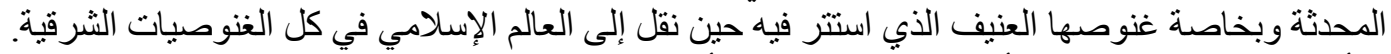

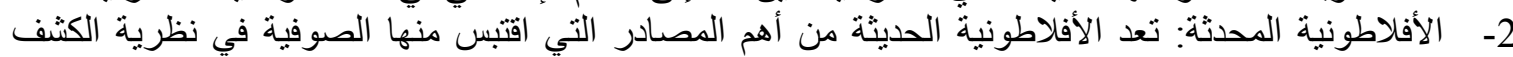

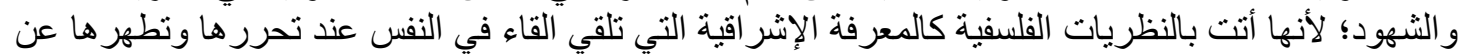

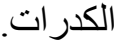

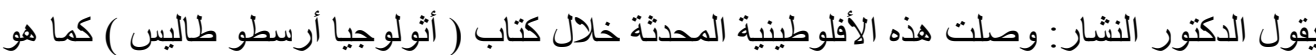

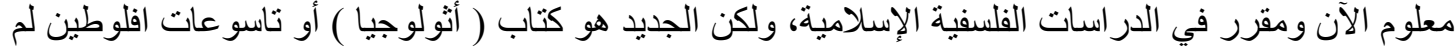

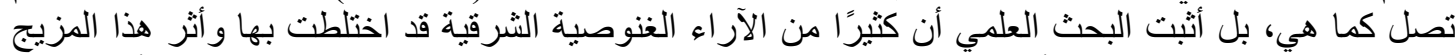

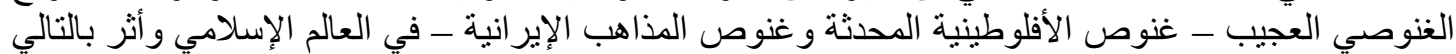

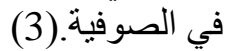

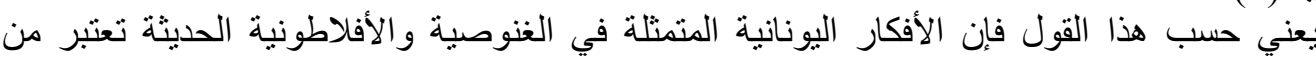

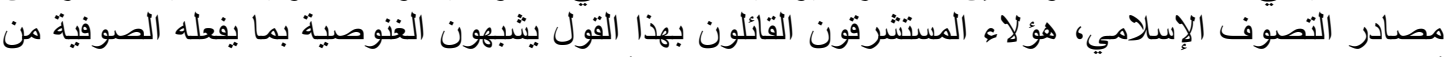

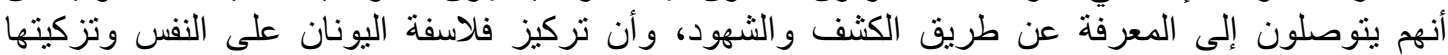

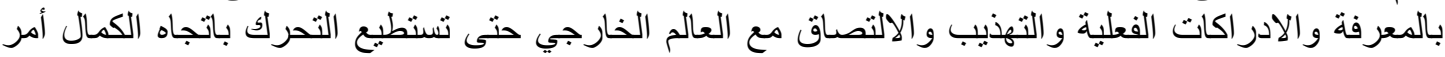

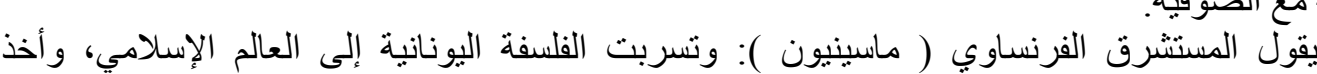

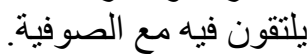

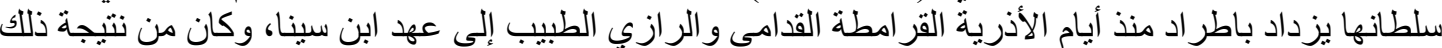

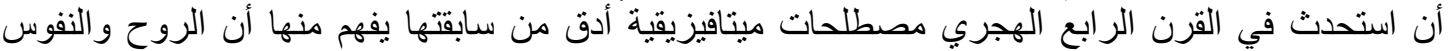
جو اهر غير مادية، وأن ثمة معاني عامة، وسلسلة من العلل الثانية وغير ذلك، وأن هذه الثيان المصطلحات اختلطت

(1) بنظر : التصوف المنشأ والمصادر: احسان الهي ظهير ، ص 121. ومدخل الى التصوف الإسلامي : د. ابو الوفا الغنيمي

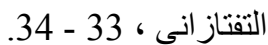

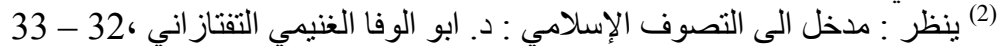
(3) بنظر : نشأة الفكر الفلسفي في الإسلام : د. علي سامي النشار ، ج 3 ، 45 - 46 ، ط 8 ، د دار المعارف 1980. 


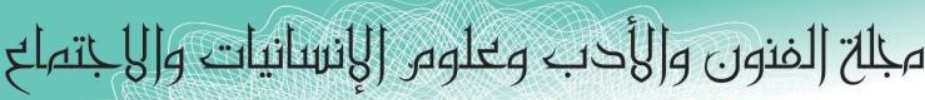
Journal of Arts, Literature, Humanities and Social Sciences

ISSN online: 2414 - 3383

ISSN print: 2616 - 3810

\section{9 نوفر \\ Volume (45)}

العدد (45)

November 2019

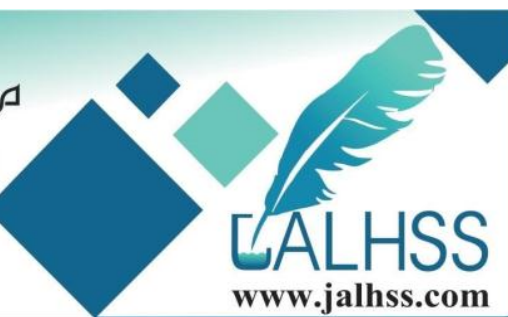

بالإلهيات المنحولة لأرسطو، وبمثل افلاطون، وفيوضات أفلوطين، وقد كان لهذا كله أثر بالغ في نطور

ولكن بعدما يقر ( نيكلسون ) بأن التصوف الإسلامي مصدره من الأفلوطينية المحدثة فهو يغير رأيه

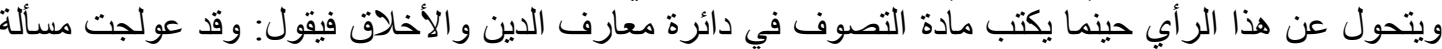

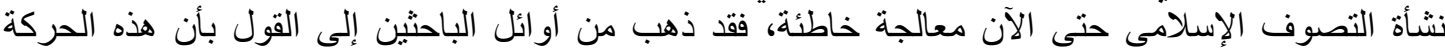

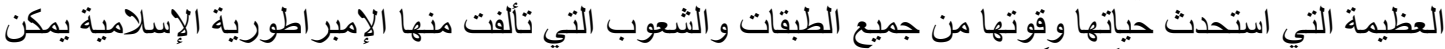

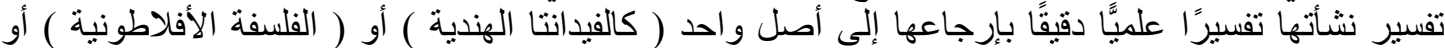

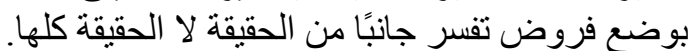
ويشرح الأستاذ ( لويس ماسينيون ) فكرة ( نيكلسون ) الأخيرة ويقول: فالحق أننا نلاحظ منذ ظهور

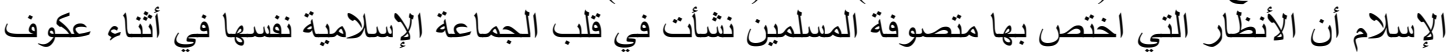

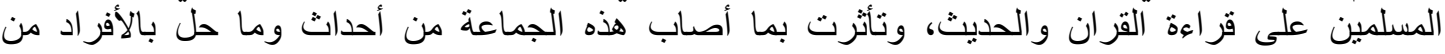

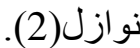
هذا حال المستشرقين؛ تارة يقولون بمصدره الأجنبي، وتارة اخرى يقولون بأن مصدره إسلامي بحت ونابع

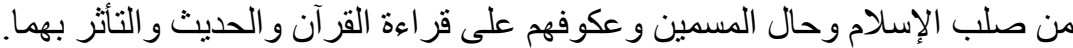

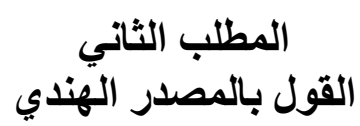

ذهب بعض المستشرقين إلى أن التصوف الإسلامي يرجع أصله إلى الديانات الهندية القديمة، ومن هؤلاء المستشرقين ( ماكس هورتن ) الذي كتب مقالات كثيرة، وظن أن التصني التصف الإسلامي أصله من الديانات القديمة

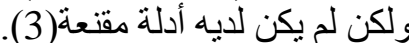

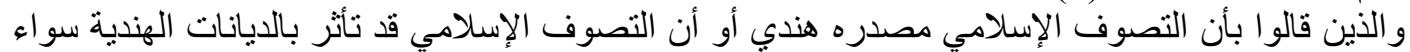

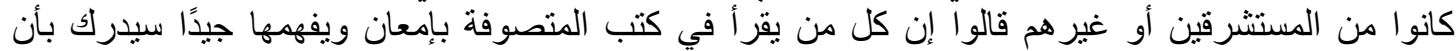

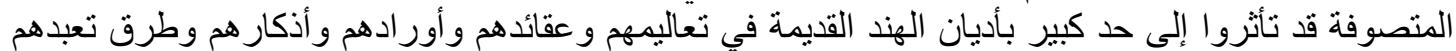

ورياضاتهم.

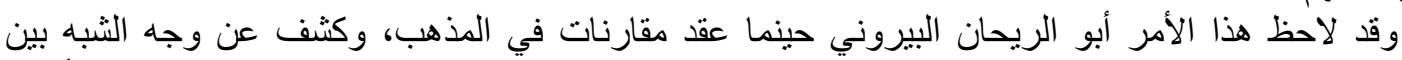

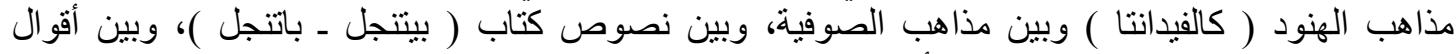

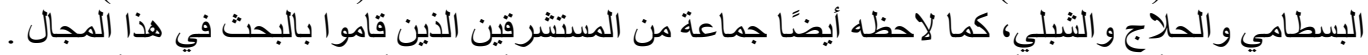

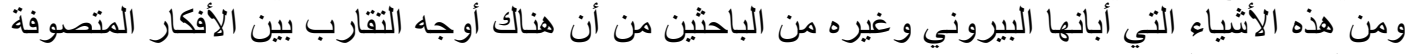

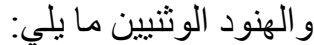
1- الحلول ووحدة الوجود: إن الاعتقاد بالحلول مأخوذ من العقائد الهندية الوثنية، فالهنود قد قالو ا بالحلول في كتبهم التي كتبها لهم الكهنة و السحرة. قال البيروني بهذا الصدد: و إلى طريق بيتنجل ذهبت الصوفية في الإشغال بالحق، ثم ذكر أمثلة لذلك من التئ

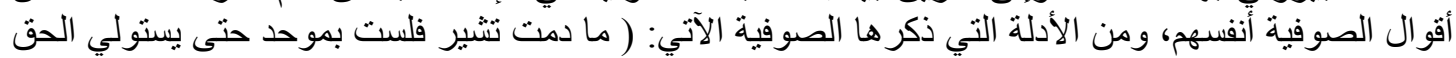

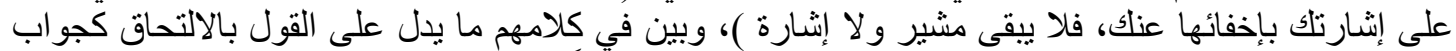

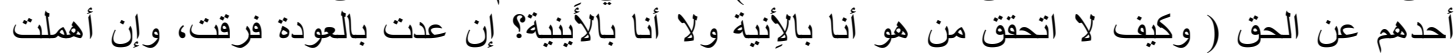
فبالإهمال خفقت وبالاتحاد الفت ).

(1) بنظر : التصوف المنشأ والمصادر : احسان الهي ظهير ، 131.

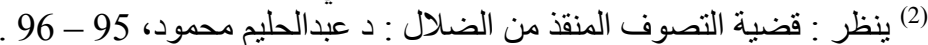

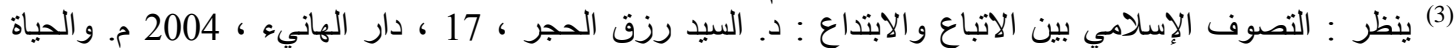

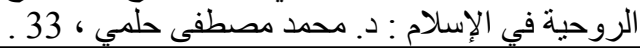




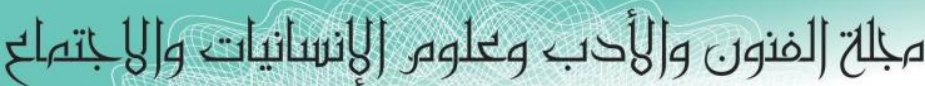

Journal of Arts, Literature, Humanities and Social Sciences

ISSN online: 2414 - 3383

ISSN print: 2616 - 3810

\section{9 نوفر Volume (45)}

(45) (40)

November 2019

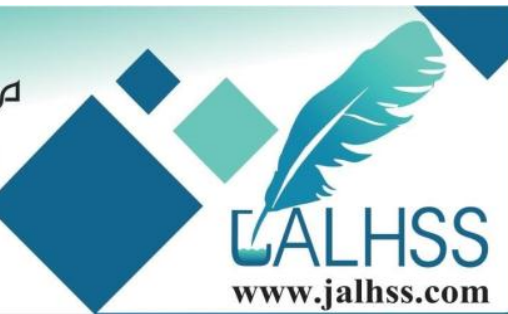

ومن الأدلة التي ذكر ها البيروني على قول الصوفية بالحلول منأثرين بأديان الهند القديمة قول الثلبي: (

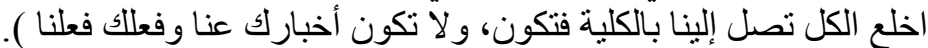

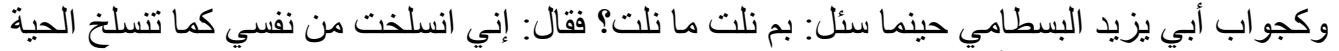

من جلدها، ثم نظرت إلى ذاتي فإذاذا أنا هو (1).

2- تعذيب النفس وحرمانها من الحياة السعيدة: أخذت المتصوفة فئنة نظرية تعذيب النفس وتحميلها أكثر مما تطيقه،

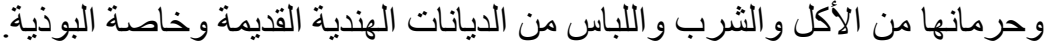

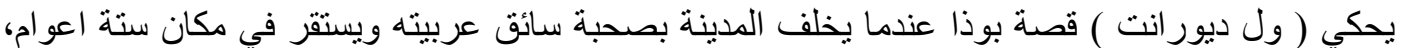

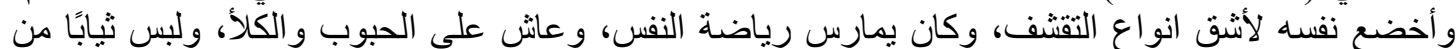

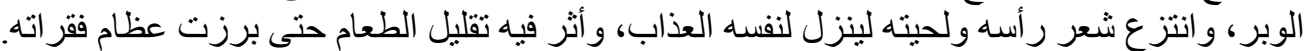

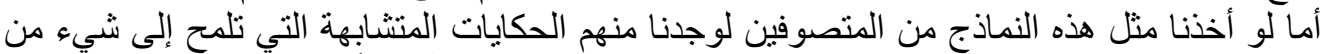

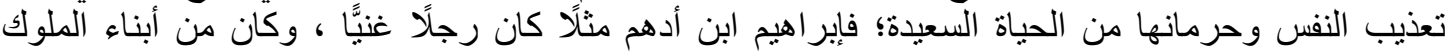

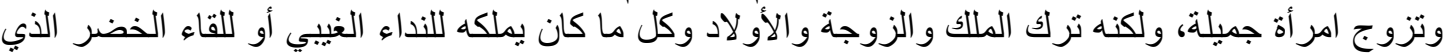

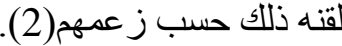
وذكر الطوسي بأن الثلبي كان يكتحل بالملح ليعتاد السهر و لا يأخذه النوم، وأحيانًا كان يحمي الميل فيكتحل

فالقائلون بهذا القول استدلو ا بمثل هذه الادلة على أن التصوف الإسلامي مصدره هندي.

\section{المطلب الثالث \\ القول بالمصدر الفارسي الثمب}

تطرقنا من قبل إلى بيان الأقوال المتشعبة حول مصدر التصوف الإسلامي، ومن هذه الأقوال القول بأن مصادر التصوف الإسلامية فارسية. وحجتهم في ذلك أنه كان هنالك صلات بين الهند وفارس، وبعد الفتوحات الإسلامية الواسعة ودخول العديد

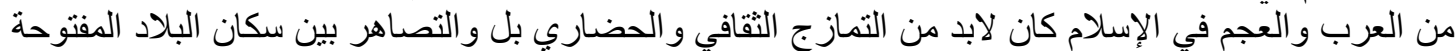

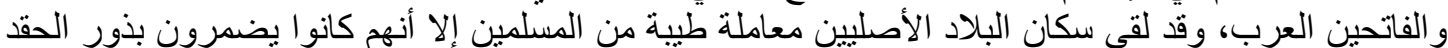

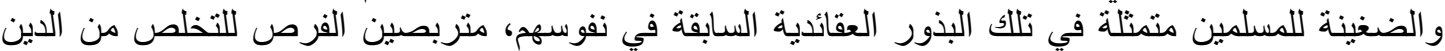

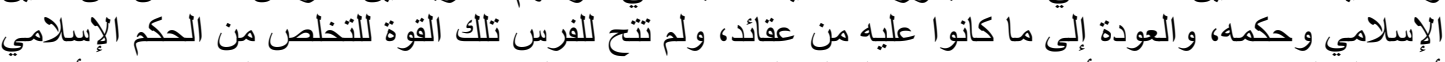

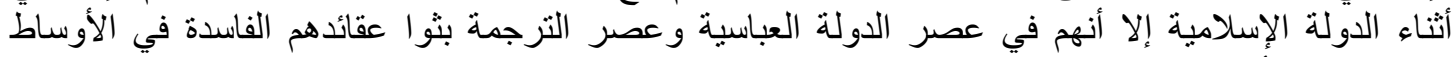

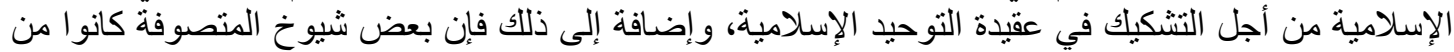
الفرس وكان لهم أثر هم البالغ في العقيدة الإسلامية. القائلون بأن التصوف مصدره الترهان فارسي ذكروا أن للتصوف الفارسي أثر في التصوف الإسلامي و أجملوه في

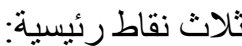

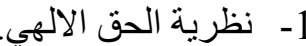

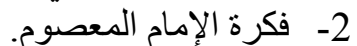

3- القول بالحقيقة المحمدية : وقد قال به المتصوفة الفلاسفة فذهبو إلى القول بأن الحقبقة المحمدية هي مبدأ خلق

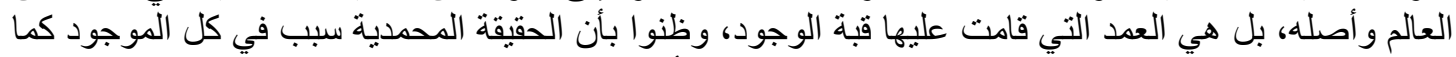

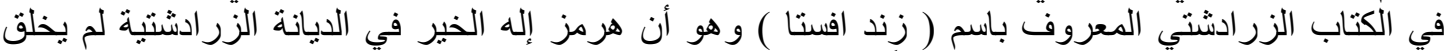
الكون بما فيه من كائنات روحية ومادية خلقًا مباشرًا بل خلقه بل بو اسطة الكلمة الكرة الإلهية.

(1) ينظر : الحياة الروحية في الإسلام : د ـ محد مصطفى حلمي ، 40 - 49 ـ 40 .

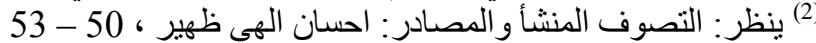
(3) اللمع: ابو نصر السراج الطوسي ، تحقيق : عبدالحليم محمود وطه عبدالباقي سرور ، 275 


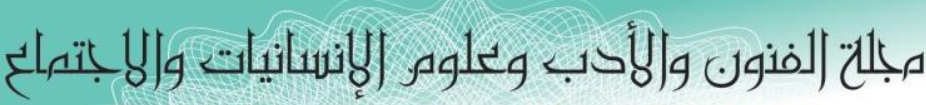
Journal of Arts, Literature, Humanities and Social Sciences

ISSN online: 2414 - 3383

ISSN print: 2616 - 3810

\section{9 نوفمبر Volume (45)}

العدد (45) November 2019

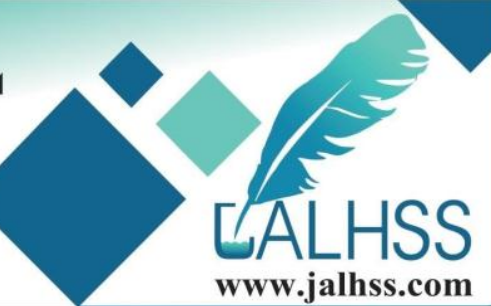

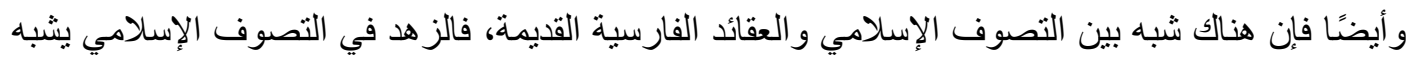

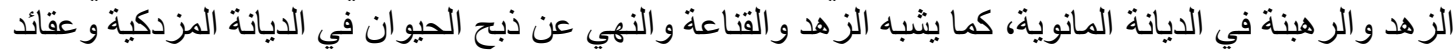

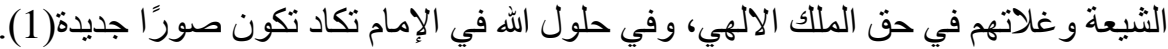

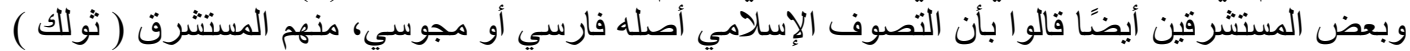

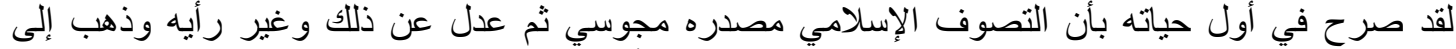
الطريق المقابل، وقال: إن التصوف وكل مان فيه من الأفكار المتطرفة يمكن الرجوع به إلى اللى تعاليم

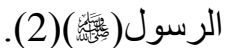

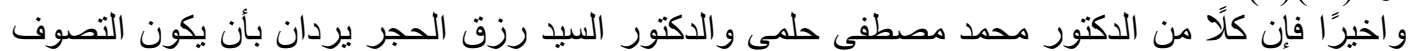

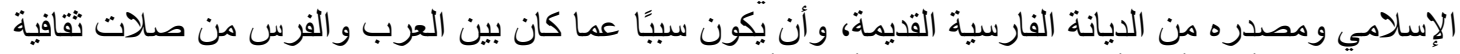

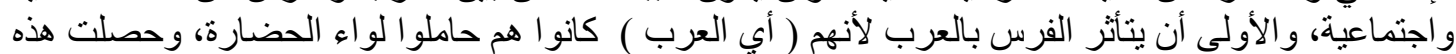

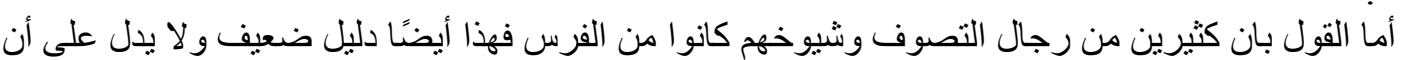
التصوف الإسلامي مصدره الديانة الفارسية القديمة لأنه كان عدد اكبر من المنصوفة التئ ورجالهم وشيوخهم كانوا أما التشابه بين الديانتين فهذه ايضًا لا يستدل به؛ لأن هذا التشابه أحيانا يرجع إلى السلوك الإنساني إزاء عربًا.

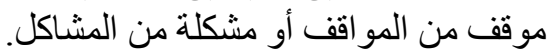

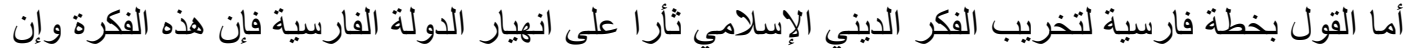

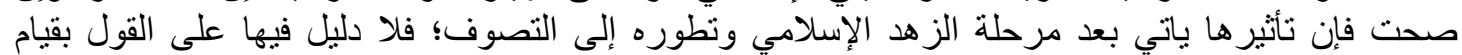

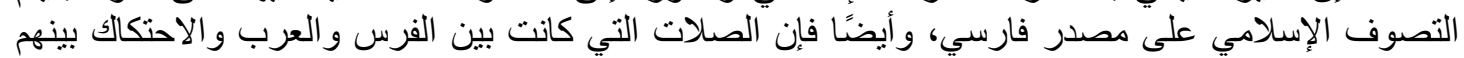

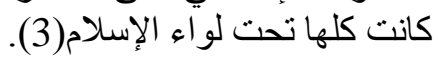

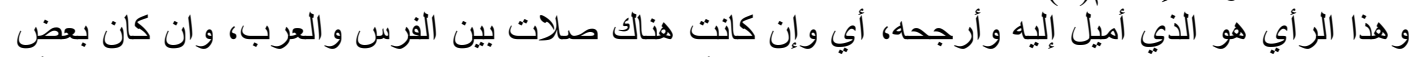

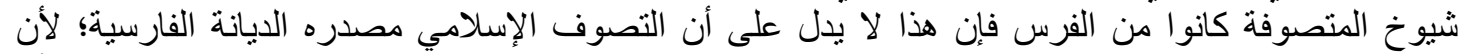

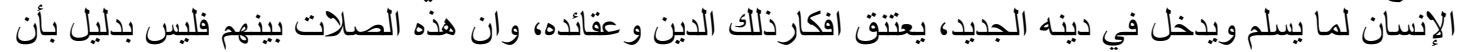
التصوف الإسلامي من الديانة الفارسية.

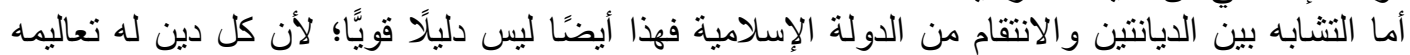

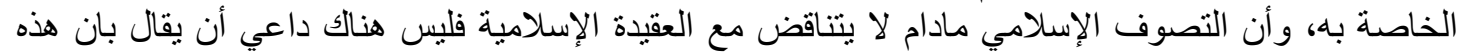

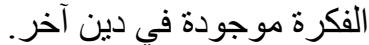

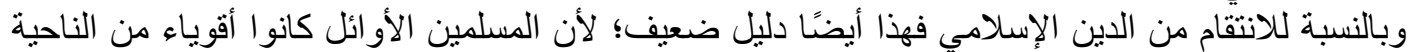
الإيمانية، وكانو ا حريصين على الإسلام؛ فلم تكن هناك ثغرة لإدخال الأفكار الأجنبية فيه.

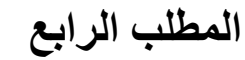 القول بالمصدر الثيعي}

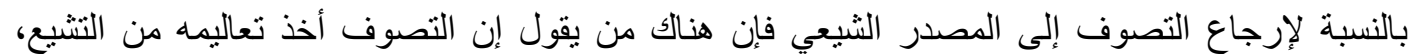

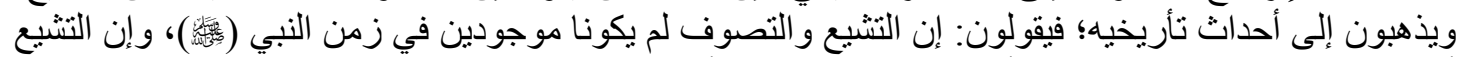

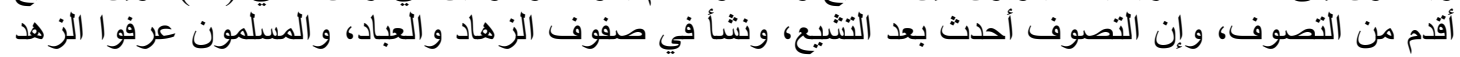

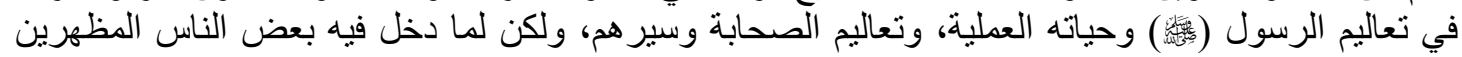

(1) ينظر : موقف الإسلام من التصوف: (رسالة ماجستير) : عمر عطا الله ابو اصبع ، 161 - 162. و الحباة الروحية في

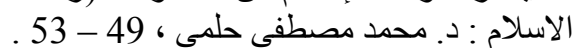

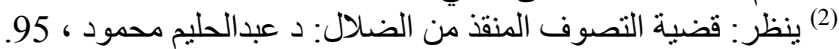

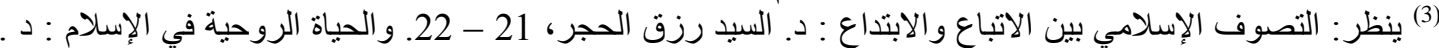
محمد مصطفى حلمي ، 


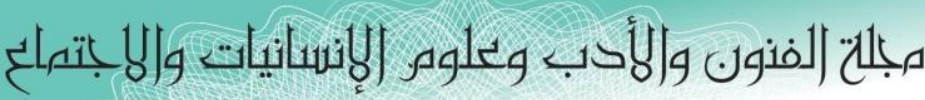
Journal of Arts, Literature, Humanities and Social Sciences

ISSN online: 2414 - 3383

ISSN print: 2616 - 3810

\section{9 نوفر Volume (45)}

(45) (40) November 2019

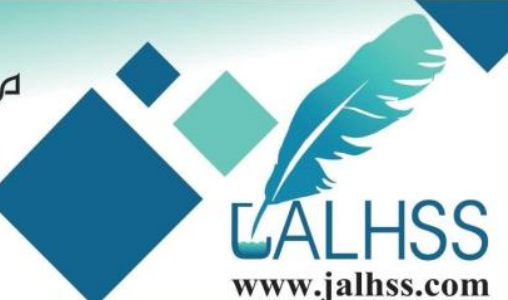

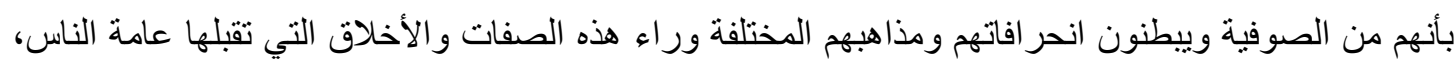

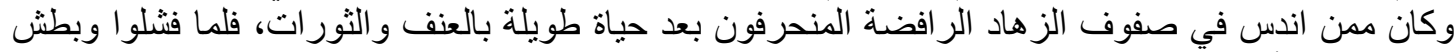

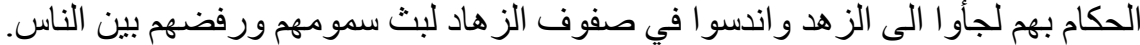

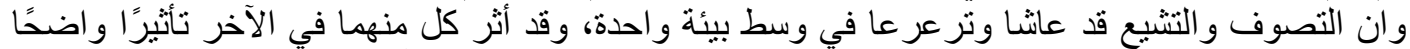

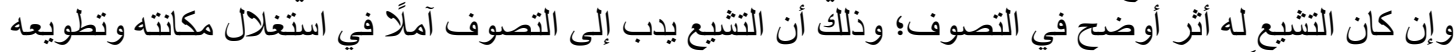

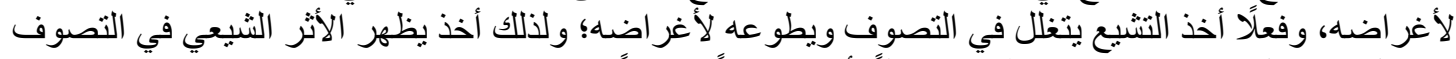

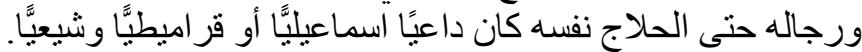

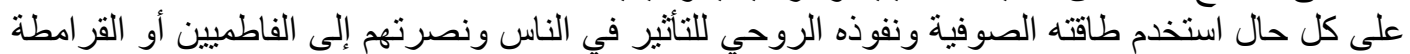

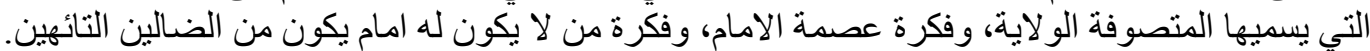

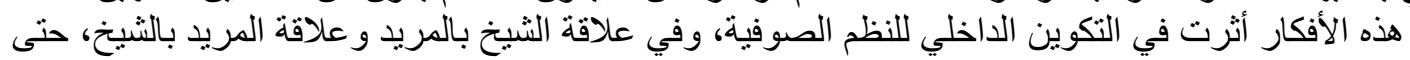

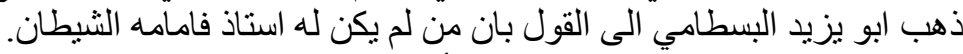

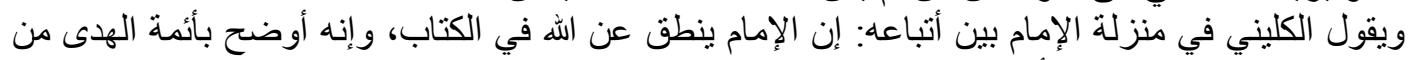

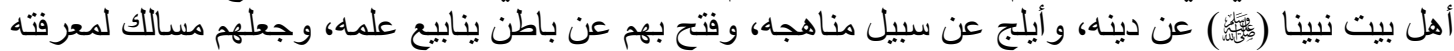

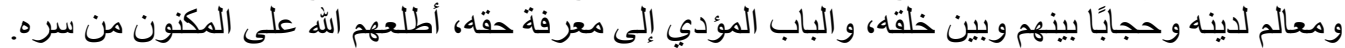

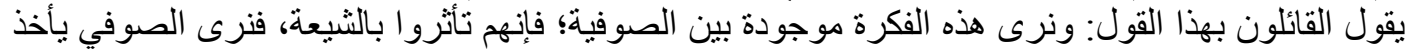

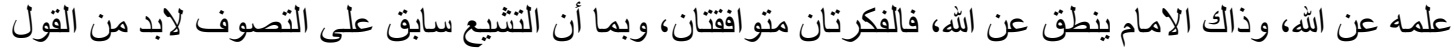

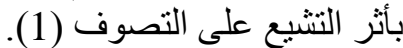

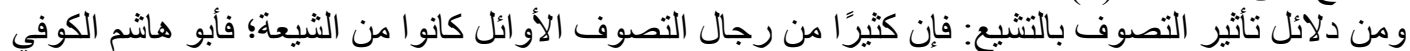

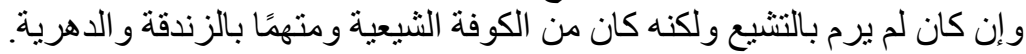

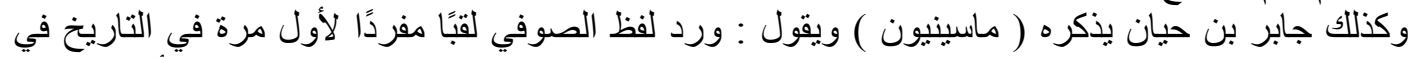
النصف الثاني من القرن الثاني الميلادي؛ إذ نعت به جابر بن حيان؛ و هو صان صاحب كيمياء شيعي من أهل الكوفة،

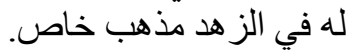

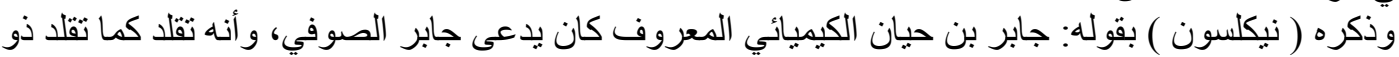

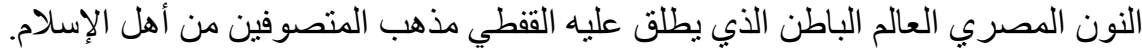

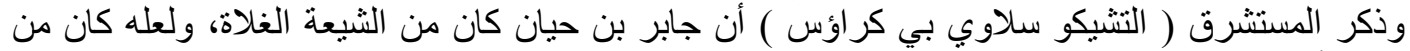

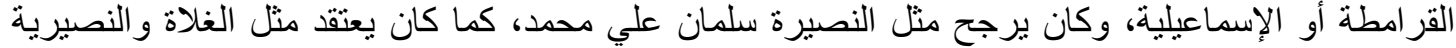
عقيدة تناسخ الأرواح. وينقل هذا المستشرق عن جابر بن حيان نفسه أنه يقول: إنه أخذ جميع علومه عن جعفر الصادق معدن الحكمة، و أنه ليس إلا الناقل المحض ون والمن والمرتب.

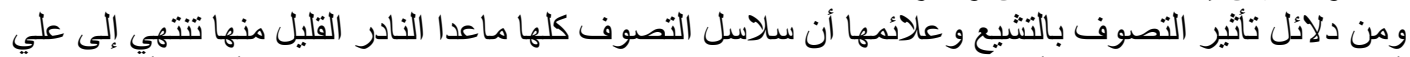

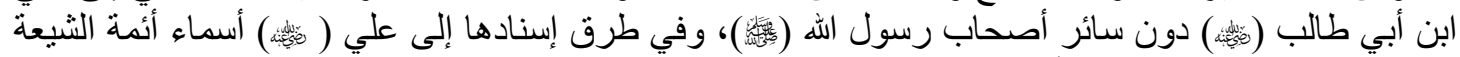

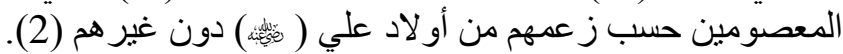

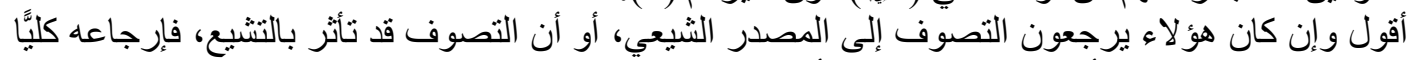

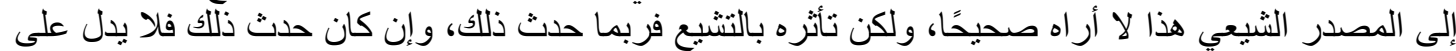

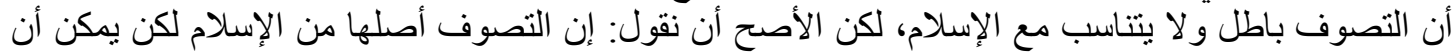

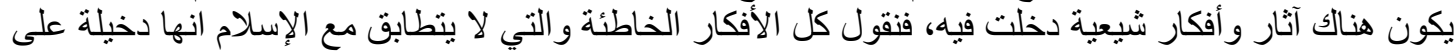
التصوف الإسلامي و لابد من تنقيته منها.

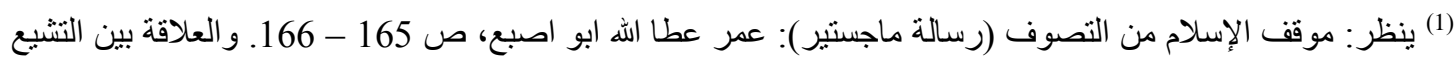

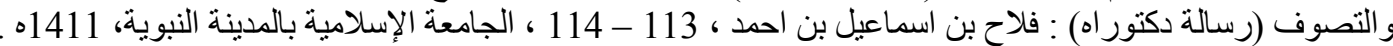
(2) ينظر : التصوف المنسأ والمصادر: الحسان الهي ظهير ، 147. و والعلاقة بين التشيع والتصوف ( رسالة دكتور اه ) ) :

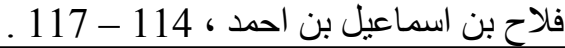




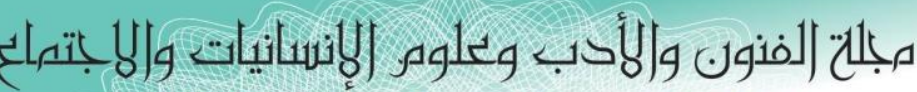
Journal of Arts, Literature, Humanities and Social Sciences

ISSN online: 2414 - 3383

ISSN print: 2616 - 3810

\section{9 نوفهبر \\ Volume (45)}

العدد (45) November 2019

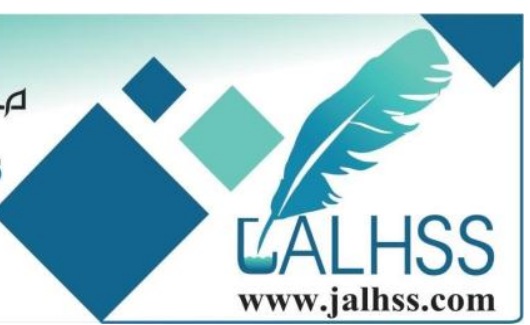

الخاتمة

عندما يكتب الإنسان في موضوع ما ويتعمق فيه يو اجهه الكثير من الصعوبات، و لال بد أن يجتهد الإنسان

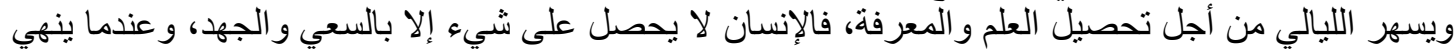

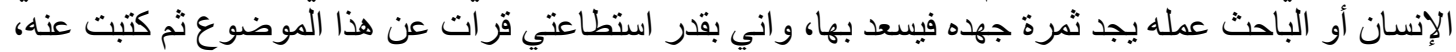

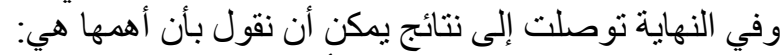

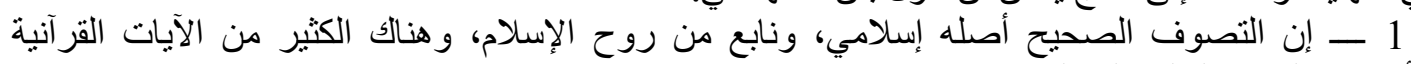
و الأحاديث النبوية الدالة على الز هد.

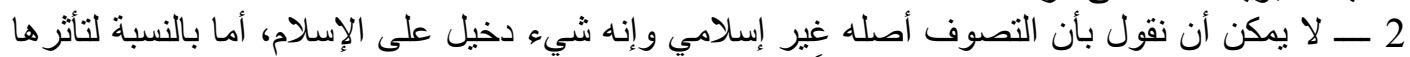

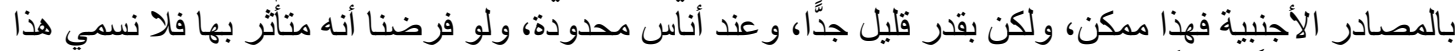

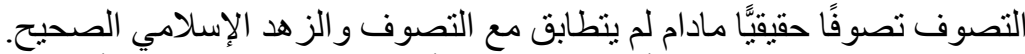

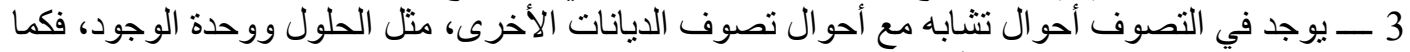

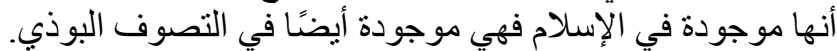

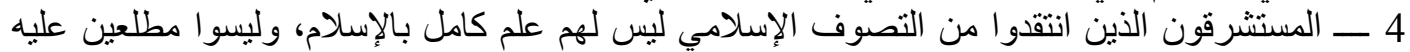

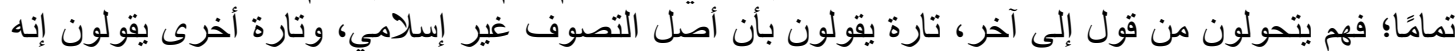

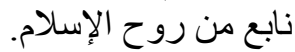

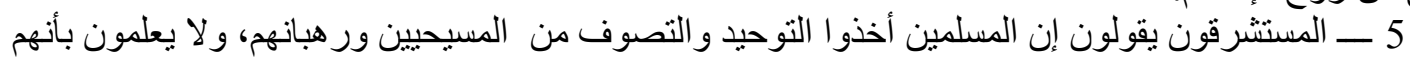

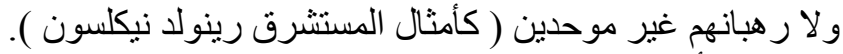

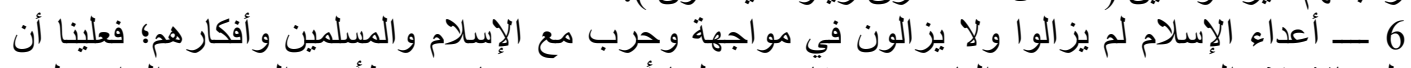

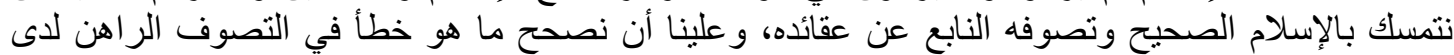
بعض الناس، وأن ننبذ الأفكار غير الصحيحة ومما ابتدعه المبتدعون.

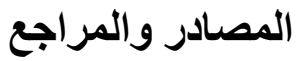
القرآن الكريم 1- الأعلام قاموس تراجم لأنشهر الرجال و النساء من العرب المستعربين والمستشرقين: خير الدين الزركلي،

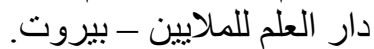

2- التصوف الإسلامي الطريق و الرجال: د. فيصل بدير عون، دار الثقافة القاهرة، 1983.

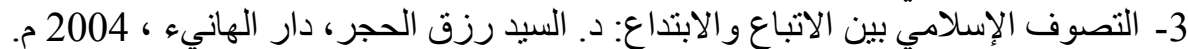

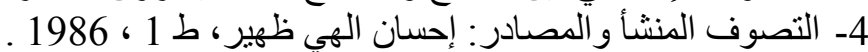
5- التصوف في القرنين الثاني و الثالث الهجريين الثرين وموقف الفقهاء منه ( رسالة دكتور اه اه ): ابو الخير نراسون،

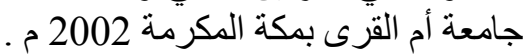

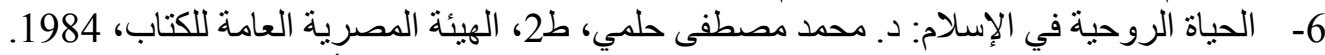
7- العلاقة بين التشيع و التصوف (رسالة دكتور اه): فلآح بن إسماعيل طالئل بن أحمد ، الجامعة الإسلامية بالمدينة

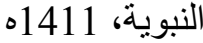

8- اللمع: أبو نصر السر اج الطوسي، تحقيق: د. عبدالحليم محمود و طه عبدالباقي سرور، مطبعة السعادة ـ

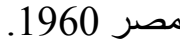

9- المعجم الكبير: سليمان بن أحمد أبو القاسم الطبراني، تحقيق: حمدي بن عبدالحميد السلفي، ط 2، مكتبة

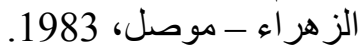

10- سنن أبي داود: سليمان بن الأشعث أبو داود السجستاني، تحقيق: محمد محي الدين عبدالحميد، دار الفكر

$$
\text { بيروت. }
$$

11- بحيح البخاري: محمد بن إسماعيل أبو عبداله البخاري، تحقيق: مصطفى ديب البخا، ط 3، دار ابن كثير، 1987. 12- ـحيح مسلم: مسلم بن الحجاج أبو الحسين القتيري النيسابوري، تحقيق: محمد فؤاد عبدالباقي، دار احياء التراث العربي، بيروت ــ لبنان. 


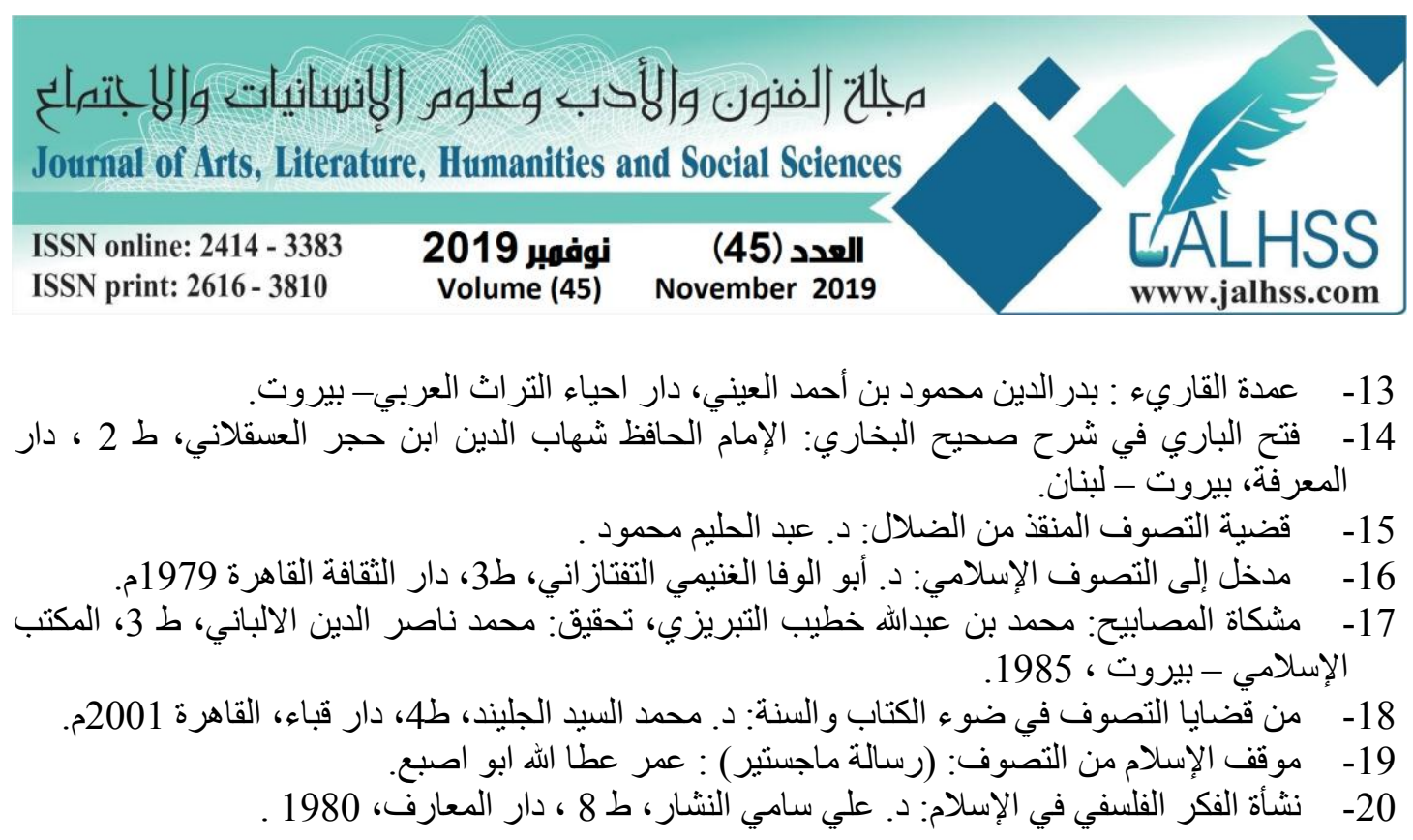

\section{References}

1 - Flags Dictionary of translations of the most famous Arab men and women Arabists and Orientalists: Khair al-Din Zarkali, House of Science for millions - Beirut.

2 - Islamic Sufism Road and men: d. Faisal Bedair Aoun, Cairo Culture House, 1983.

3 - Islamic Sufism between followers and innovation: d. Mr. Rizk Al-Hajar, Dar AlHani, 2004.

4 - Sufism origin and sources: Ihsan Ghi Zaheer, 1986.

5 - Sufism in the second and third centuries AH and the position of the jurists from it (Ph.D.): Abulkhair Tarson, Umm Al-Qura University, Makkah, 2002.

6 - Spiritual Life in Islam: d. Mohamed Mostafa Helmy, Egyptian Book Organization, 1984.

7 - Relationship between Shiism and Sufism (Ph.D.): Falah bin Ismail bin Ahmed, the Islamic University in the city of the Prophet, $1411 \mathrm{e}$

8- Shining: Abu Nasr Al-Seraj Al-Tusi, investigation: d. Abdel Halim Mahmoud and Taha Abdelbagi Sorour, Al-Saada Press - Egypt 1960.

9- The Great Dictionary: Suleiman bin Ahmad Abu al-Qasim al-Tabarani.

10 - Sunan Abu Dawood: Suleiman ibn al-Ash'ath Abu Dawood al-Sijistani, investigation: Mohammed Mohiuddin Abdul Hamid, Dar al-Fikr Beirut.

11 - Sahih al-Bukhari: Mohammed bin Ismail Abu Abdullah al-Bukhari, the investigation: Mustafa Deeb al-Bagha, i 3, Dar Ibn Katheer, 1987.

12 - Sahih Muslim: Muslim bin pilgrims Abu Hussein al-Qushayri Nisaburi, the investigation: Mohammed Fouad Abdul Baqi, Dar revival of Arab heritage, Beirut Lebanon.

13 - Mayor of the reader: Badreddine Mahmoud bin Ahmed Al-Aini, Dar revival of Arab heritage - Beirut.

14 - Fath al-Bari in explaining Sahih al-Bukhari: Imam al-Hafiz Shihab al-Din Ibn Hajar al-Askalani, Dar al-Maarefa, Beirut - Lebanon

15. The issue of mysticism saved from misguidance: d. AbdulHAlim MAhloud, Free Membership.

16 - Introduction to Islamic Sufism: d. Abu Wafa Ghanimi Taftazani, Cairo Culture House 1979. 


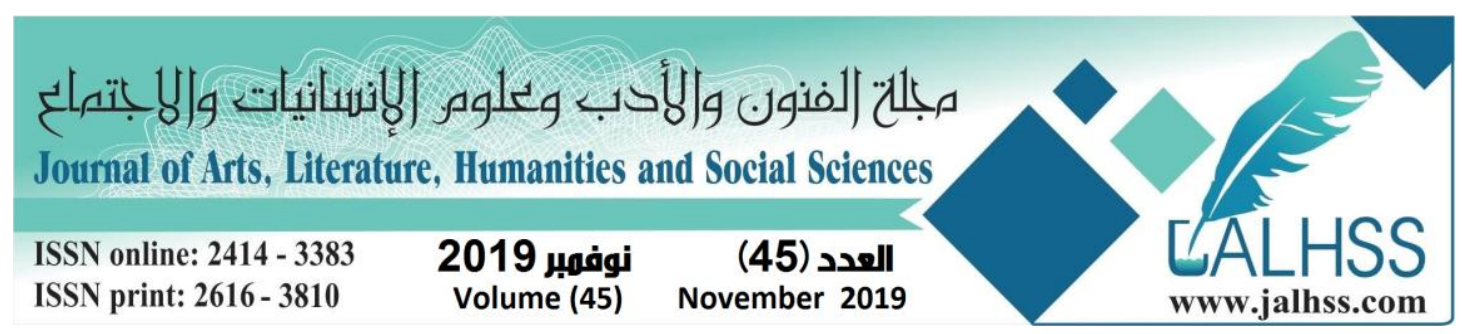

17- Mishkat al-Misbah: Muhammad ibn Abdallah Khatib al-Tabrizi, Investigation: Mohammed Nasser al-Din al-Albani, Islamic Bureau, Beirut, 1985.

18 - Of the issues of mysticism in the light of the book and the year: d. Mohamed El Sayed El-Glind, 4th floor, Dar Qubaa, Cairo 2001.

19 - The position of Islam from Sufism: (Master): Omar Atallah Abu finger.

20 - the emergence of philosophical thought in Islam: d. Ali Sami Al-Nashar, 8th floor, Dar Al-Maaref, 1980. 